\title{
1 Spatial variability of extreme rainfall at radar subpixel scale
}

\section{Authors}

4 Nadav Peleg ${ }^{1}$, Francesco Marra ${ }^{2}$, Simone Fatichi ${ }^{1}$, Athanasios Paschalis ${ }^{3}$, Peter Molnar ${ }^{1}$, 5 Paolo Burlando ${ }^{1}$

$6{ }^{1}$ Institute of Environmental Engineering, ETH Zürich, Switzerland

$7 \quad{ }^{2}$ Department of Geography, Hebrew University of Jerusalem, Israel

$8{ }^{3}$ Faculty of the Engineering and the Environment, University of Southampton, UK

11 Extreme rainfall is quantified in engineering practice using Intensity-Duration-

12 Frequency curves (IDF) that are traditionally derived from rain-gauges and more 13 recently also from remote sensing instruments, such as weather radars. These 14 instruments measure rainfall at different spatial scales: rain-gauge samples rainfall at 15 the point scale while weather radar averages precipitation on a relatively large area, 16 generally around $1 \mathrm{~km}^{2}$. As such, a radar derived IDF curve is representative of the mean

17 areal rainfall over a given radar pixel and neglects the within-pixel rainfall variability. In

18 this study, we quantify subpixel variability of extreme rainfall by using a novel space-

19 time rainfall generator (STREAP model) that downscales in space the rainfall within a 
20 given radar pixel. The study was conducted using a unique radar data record (23 years)

21 and a very dense rain-gauge network in the Eastern Mediterranean area (northern

22 Israel). Radar-IDF curves, together with an ensemble of point-based IDF curves

23 representing the radar subpixel extreme rainfall variability, were developed fitting

24 Generalized Extreme Value (GEV) distributions to annual rainfall maxima. It was found

25 that the mean areal extreme rainfall derived from the radar underestimate most of the

26 extreme values computed for point locations within the radar pixel (on average, $70 \%$ ).

27 The subpixel variability of rainfall extreme was found to increase with longer return

28 periods and shorter durations (e.g. from a maximum variability of $10 \%$ for a return

29 period of 2 years and a duration of $4 \mathrm{~h}$ to $30 \%$ for 50 years return period and 20 min

30 duration). For the longer return periods, a considerable enhancement of extreme

31 rainfall variability was found when stochastic (natural) climate variability was taken into

32 account. Bounding the range of the subpixel extreme rainfall derived from radar-IDF can

33 be of a major importance for different applications that require very local estimates of

34 rainfall extremes.

35

36 Key words

37 Extreme rainfall variability; high resolution rainfall modelling; IDF curves; precipitation

38 downscaling; sub pixel scale; weather radar

39

$40 \quad 1$ Introduction 
41 Extreme rainfall is often quantified using Intensity (or Depth)-Duration-Frequency

42 curves (IDF or DDF). IDF curves are essentially cumulative distribution functions of

43 rainfall intensity maxima conditioned on duration, linking the rainfall maximum intensity

44 recorded for a given duration with its return period (Coles et al., 2001; Katz et al., 2002;

45 Koutsoyiannis et al., 1998). The recent availability of relatively long records of rainfall

46 measurements from weather radars in a spatial and temporal resolution of $\sim 1 \mathrm{~km}^{2}$ and

$47 \sim 5 \mathrm{~min}$, gives the possibility to explore the inter-gauge scale patterns and variability of

48 extreme rainfall over large areas. A few contributions have been devoted to the use of

49 weather radars for analyzing rainfall extremes (e.g. Allen and DeGaetano, 2005; Durrans

50 et al., 2002; Lombardo et al., 2006; Overeem et al., 2010) and for developing IDF curves

51 based directly on radar rainfall estimates (e.g. Eldardiry et al., 2015; Marra and Morin,

52 2015; Overeem et al., 2009; Paixao et al., 2015).

Rain-gauges and weather radars are recording precipitation at different spatial

54 scales. While the former is essentially a point scale measurement, the latter refers to a

55 volume integral scale. In fact, in most cases, the ratio between observation scales (for

56 standard C-band radar and a standard rain-gauge) is in the order of $10^{7}$. This means that

57 differences between rainfall intensity for a given duration and return period are

58 expected when comparing IDF curves developed by a rain-gauge or by a weather radar

59 (gauge-IDF and radar-IDF from here on).

60

A radar-IDF curve for a given location represents the extreme of mean areal

61 rainfall over a particular radar pixel. A single value is therefore assigned for given

62 duration and return period to the radar pixel. The extreme rainfall expected in any 
single point within the radar pixel cannot be estimated directly from the radar data. At

64 the same time, quantifying the uncertainty range of the radar subpixel variability of

65 extreme rainfall around the radar-IDF curve can be of major importance for applications

66 requiring local estimates of rainfall extremes; for example, the managing and designing

67 of urban drainage systems (Gires et al., 2012; Gires et al., 2013; Gregersen et al., 2013;

68 Ochoa-Rodriguez et al., 2015; Willems et al., 2012).

One way to estimate the extreme rainfall variability is to set a large number of

70 point-scale measuring devices (i.e., rain-gauges or disdrometers) within a weather radar

71 pixel domain, recording at the same temporal resolution of the weather radar.

72 Unfortunately this approach of recording the entire "true" extreme rainfall variability is

73 not a realistic option as numerous gauges will be required. Alternatively, the "true"

74 rainfall can be assessed using a limited number of rain-gauges interspersed within the

75 subpixel domain. The number and setup of these rain-gauges can be determined using

76 reduction methods such as the Variance Reduction Factor (Krajewski et al., 2000;

77 Morrissey et al., 1995; Peleg et al., 2013; Rodríguez-Iturbe and Mejía, 1974b; Villarini et

78 al., 2008). However, dense rain-gauge networks should have been installed a priori

79 within the area of interest, recording the same period as the weather radar.

80 Unfortunately, no such dense rain-gauge networks exist today (Krajewski et al., 2010).

An alternative is to estimate the ratio between the areal average rainfall and a

82 point rainfall using Areal Reduction Factors (Rodriguez-Iturbe and Mejía, 1974a;

83 Sivapalan and Blöschl, 1998; Svensson and Jones, 2010; Veneziano and Langousis, 2005).

84 The reciprocal of the reduction factor may allow a good estimation of the mean extreme 
rainfall in one point from weather radar, but it cannot assess the extreme rainfall spatial variability.

In this study, we explicitly quantify the radar subpixel variability of extreme rainfall by using the STREAP (Space-Time Realizations of Areal Precipitation) model to

89 downscale recorded radar rainfall over a given pixel. STREAP is a novel stochastic rainfall 90 generator able to simulate high-resolution rainfall fields while preserving the rainfall 91 spatio-temporal structure and statistical characteristics (Paschalis, 2013; Paschalis et al., 92 2014; Paschalis et al., 2013). While the model is conceived as a precipitation generator, 93 here it is essentially used only for spatial-disaggregation since the external storm 94 properties are prescribed from observations. The STREAP model is calibrated and 95 validated using a dense rain-gauge network covering the typical scale of remote-sensing 96 devices $\left(\sim 4 \mathrm{~km}^{2}\right)$. Afterwards, we use the STREAP model to downscale the radar rainfall 97 record from the pixel scale $\left(1 \mathrm{~km}^{2}\right)$ to subpixel scale $\left(10^{-4} \mathrm{~km}^{2}\right)$ and we estimate the 98 extreme rainfall variability of subpixels. Finally, we compute how well the temporal 99 variability of extreme rainfall that was simulated starting from the radar observations represents the current stochastic (natural) climate variability by applying a

101 bootstrapping technique on the simulated record. Throughout this study we consider 102 the radar data to represent the "true" mean areal rainfall. The instrumental errors 103 related to weather radar and dense rain-gauge network data were discussed previously 104 by Peleg et al. (2013) and by Marra and Morin (2015) and are not further analyzed here. 
108 A dense rain-gauge network covering an area of $4.41 \mathrm{~km}^{2}$ was deployed in November 1092011 near Kibbutz Galed (Israel), about $15 \mathrm{~km}$ east of the Mediterranean coastline (Fig. 110 1). The network has been fully described by Peleg et al. (2013) and here a brief summary 111 is given. The network consists of 26 tipping bucket rain-gauges located at 13 different 112 stations maintained by the Hydrometeorology Lab of the Hebrew University of 113 Jerusalem. At each station two gauges separated by a distance of $1 \mathrm{~m}$, as suggested by 114 Ciach and Krajewski (1999) and Krajewski et al. (2003), were installed to maintain good 115 quality control (QC). The rain-stations are non-uniformly distributed, due to the terrain 116 limitations, with intra-distances between 57 and 2,672 $\mathrm{m}$. The sampling resolution of 117 the gauges is 1 minute, aggregated from a resolution of $0.1 \mathrm{~mm}$ per tip (accuracy of $3 \%$ 118 up to $50 \mathrm{~mm} \mathrm{~h}^{-1}$ ). To the best of our knowledge, this is the only rain-gauge network 119 located in a Mediterranean climate, with such a high gauge density, although a few 120 similar spatially distributed networks are located in other climates (Ciach and Krajewski, 121 2006; Fiener and Auerswald, 2009; Jaffrain and Berne, 2012; Jensen and Pedersen, 122 2005; Pedersen et al., 2010).

In this study, rainfall records collected from 1 November 2011 to 1 May 2015 are 124 used; the total spatially averaged rainfall accumulation was 1,191 mm divided into 137 125 rain events. Separation between rain events was done considering a minimum of 6 hour 126 dry period. Rain events with cumulative rainfall depth less than $0.5 \mathrm{~mm}$ or with fewer 
127 than 9 stations recording rain (out of 13) are excluded. An inherent problem with

128 tipping-bucket-gauges is that only the time at which the bucket is completely filled is

129 recorded and no information is available on the actual period of time necessary for the

130 filling. To overcome this problem, a backward linear interpolation to the previous

131 recorded tip was applied (Peleg et al., 2013).

Strict QC procedures are conducted to minimize the measurement errors. Every

133 minute the rainfall intensities measured by the two rain-gauges of each station are

134 compared; if the difference exceeds $0.2 \mathrm{~mm}$ (two ticks per minute), the entire record of

135 the station for the specific rainfall event is considered to be corrupted and is removed.

136 The root mean square error of the rain-stations is found by

$137 \quad R M S E=\sqrt{\frac{1}{N} \sum_{i=1}^{N}\left(g_{1}^{i}-g_{2}^{i}\right)^{2}}$

138 where $N$ is the sample size and $g_{1}^{i}$ and $g_{2}^{i}$ are the $i$-th rain-gauge measurements of the

139 two gauges at each rain-station, while recording rain. The RMSE found for all stations

140 after QC is very small, in a range between $0.0278 \mathrm{~mm} \mathrm{~min}^{-1}$ and $0.0312 \mathrm{~mm} \mathrm{~min}^{-1}$ (out of

141 the maximum error possible of $0.2 \mathrm{~mm} \mathrm{~min}^{-1}$ ).

$142 \quad 2.2$ Weather radar

143 The E.M.S company weather radar system, a C-Band (5.35 cm wavelength) non-Doppler

144 instrument, located about $63 \mathrm{~km}$ south of the dense rain-gauge network, is used in this

145 study; data from this radar have been extensively used for climatological and 146 hydrological studies in the past (Karklinsky and Morin, 2006; Marra and Morin, 2015; 
147 Morin et al., 2001; Morin and Gabella, 2007; Peleg et al., 2013; Peleg and Morin, 2012;

148 Peleg and Morin, 2014; Rozalis et al., 2010). The system was deployed in the late '80s 149 and archives data since October 1990, providing almost continuous data records for 23 150 years (1990-2013). Small data gaps exist due to short periods of radar malfunction and 151 regular maintenance. The radar observation geometry is characterized by a spatial 152 resolution of $1.4^{\circ} \times 1 \mathrm{~km}$ and a temporal resolution of 5 min per volume scan. Radar quantitative precipitation estimation (QPE) is obtained applying a 154 combination of (1) physically based corrections, accounting for errors due to antenna 155 pointing, ground echoes, wet radome attenuation, beam blockage, attenuation, vertical 156 profile reflectivity and (2) quantitative adjustments based on the comparison with rain157 gauge measurements of the official Israel Meteorological Service network, i.e. excluding 158 gauges from the network presented above (Marra and Morin, 2015; Marra et al., 2014; 159 Morin and Gabella, 2007). A fixed reflectivity to rain rate conversion Z-R relationship of $160 \mathrm{Z}=316 \mathrm{R}^{1.5}\left(\mathrm{Z}\right.$ in $\mathrm{mm}^{6} \mathrm{~m}^{-3}, \mathrm{R}$ in $\left.\mathrm{mm} \mathrm{h}^{-1}\right)$, which follows previous radar studies over the area 161 (Morin and Gabella, 2007; Peleg and Morin, 2012), is used and the radar data are 162 converted to a 1-km² Cartesian grid. A detailed description of the correction procedure 163 and assessment of the accuracy of the QPE can be found in Marra and Morin (2015). The analysis was conducted on a single radar pixel partly covering the area 165 sampled by the dense rain-gauge network (Domain B in Fig. 1). A total of 14,231 mm of 166 rainfall were recorded between the years 1990 and 2013 and are divided into 585 rain 167 events, i.e. an average of $24.3 \mathrm{~mm}$ per event. 
170 The gap between the remote sensing scale (weather radar or satellite) and the point

171 scale (disdrometer or rain-gauge) can be bridged using downscaling approaches. Here,

172 we take advantage of the STREAP model (sub-section 3.1), a high-resolution space-time 173 rainfall generator, to stochastically downscale the observed radar rainfall. The subpixel 174 extreme rainfall variability is estimated constructing IDF curves based on the ensemble 175 of downscaled rainfall time series in multiple points. Two domains are set up for the 176 downscaling procedure (Fig. 1). Domain A is used for training, i.e., for the calibration and 177 validation of the STREAP model. This domain is composed of a network of 44,100 virtual 178 rain-gauges (simulated using the STREAP model) by discretizing the $2.1 \times 2.1 \mathrm{~km}^{2}$ 179 domain into $10 \times 10 \mathrm{~m}^{2}$ pixels, covering the same domain of the actual dense rain-gauge 180 network (nearly 4 years of observations). Domain B is used for the downscaling of 181 rainfall from the radar pixel scale to nearly point scale (Figs. 1 and 2); it is the nearest 182 radar pixel covering the gauge network. A network of 10,000 virtual rain-gauges is 183 simulated discretizing the $1 \times 1 \mathrm{~km}^{2}$ radar pixel (23 years of observations) into $10 \times 10$ $184 \mathrm{~m}^{2}$ pixels. A spatial scale of $10 \times 10 \mathrm{~m}^{2}$ can be considered point scale because below this 185 resolution changes in the spatial correlation of the rainfall are very small (e.g. $\sim 0.5 \%$ for 186 a 1 min time scale, see Peleg et al., 2013) and the rainfall spatial variability is 187 substantially suppressed. The ensemble of downscaled point rainfall time series, i.e. 188 virtual rain-gauges that are simulated using the STREAP model in Domain $\mathrm{B}$, is used to 189 compute the IDF curves (Fig. 2), and represents a quantitative estimate of the subpixel 
rainfall variability (sub-section 3.2). Last, bootstrapping is applied to the simulated

191 rainfall record in order to generate samples representing the stochastic (natural) climate

192 variability, which is then compared with the single realization recorded by the radar 193 (sub-section 3.3).

196 The STREAP model is a rainfall generator designed for simulating high-resolution rainfall 197 fields while preserving the rainfall spatio-temporal structure and statistical properties 198 (Paschalis, 2013; Paschalis et al., 2014; Paschalis et al., 2013). It is a substantial 199 improvement of the previous works of Bell (1987) and Kundu and Bell (2003) and mainly 200 of the String of Beads model (Pegram and Clothier, 2001a; Pegram and Clothier, 2001b).

201 It is composed of three hierarchical modules: (a) a storm arrival process; (b) temporal 202 evolution of the mean areal intensity and fraction of wet area during a storm; and (c) 203 evolution of the space-time structure of rainfall during a storm.

$204 \quad 3.1 .1$ General setting of the STREAP model

205 The STREAP model and its calibration process using weather radar products were 206 discussed in detail by Paschalis (2013) and Paschalis et al. (2013). Here we present only 207 the modifications that are made to tailor the model structure to the specific case study 208 and to set the model to a finer spatial resolution than the original application. 
In contrast to the original STREAP model, the storm arrival process (i.e., rainfall

210 event duration and timing) is not stochastically generated as the goal here is to

211 downscale rainfall of observed storms rather than generating an ensemble of new

212 storms. We used the storm arrival sequence obtained either by the dense rain-gauge

213 network, for the domain A, or by the weather radar for the domain B.

The statistics of the mean areal rainfall during a storm is defined by two

215 variables: the mean areal rainfall intensity (image mean flux, IMF) and the wet area

216 fraction (WAR). Throughout the paper we use the notation introduced by Pegram and

217 Clothier (2001a) and adopted by Paschalis et al. (2013). Originally, the IMF and WAR

218 time series are simulated as a bivariate autocorrelated stochastic processes that depend

219 also on the storm duration. Here, the observed IMF time series are used as model

220 inputs, taken as the mean of the 1-min rainfall recorded by the dense rain-gauge

221 network (domain A) or as the rainfall intensity recorded by a single radar pixel (domain

222 B). As the weather radar data recorded rainfall in time intervals larger than the rain-

223 gauges (i.e., 1 min intervals), a simple linear interpolation of the rainfall intensity from

224 the radar interval to 1 min was applied. The WAR was stochastically generated using the

225 data derived from the dense rain-gauge network as explained below. This change from

226 the original model is made due to the fact that a much denser rain-gauge network is

227 required in order to estimate the WAR autocorrelation function.

229 scheme: (i) a variable WAR $_{\mathrm{g}}$ was generated using a Gaussian distribution $\left(\mu_{\text {WAR }}, \sigma_{\text {WAR }}\right)$; 
230 (ii) WAR autocorrelation function was defined using $A R(1)$ model; and, (iii) WAR time 231 series were stochastically generated following a distribution anamorphosis 232 transformation (see for details Schleiss et al., 2009 and Schleiss et al., 2011), which 233 couples the stochastically generated $W_{A} R_{g}$ time series to the observed IMF time series 234 as:

$235 W A R(t)=\sigma_{\text {WAR }} \cdot\left(\rho_{I W} \cdot F^{-1}\left[U\left(\operatorname{IMF}_{w}(t)\right)\right]+\sqrt{1-\rho_{I W}{ }^{2}} \cdot F^{-1}\left[U\left(W A R_{g}(t)\right)\right]\right)+\mu_{\text {WAR }}$

236 where $\rho_{I W}$ is the correlation between WAR and IMF observed time series, $U\left(I M F_{w}(t)\right)$

237 is the Weibull quantile function for the IMF time series transformed using the two 238 parameters of the IMF distribution $\left(\beta_{I M F}, \alpha_{I M F}\right), U\left(W A R_{g}(t)\right)$ is the Gaussian quantile 239 function for the WAR time series which was generated using the $A R(1)$ model and 240 transformed using $\left(\mu_{A R(1)}, \sigma_{A R(1)}\right)$ and $F^{-1}$ is the Gaussian inverse cumulative probability 241 distribution function $N \sim(0,1)$. The observed WAR was estimated by applying Thiessen 242 polygons to every rain-station i.e., if a rain-station was recording rainfall at a given 243 minute, its polygon was considered wet and was added to the total wet area fraction.

244 The correlation term $\rho_{I W}$ is estimated using the mean intensity field from rain-gauge 245 data. The spatial rainfall field is simulated as a probability transformation of an 247 isotropic Gaussian random field characterized by a simple one-parameter exponential 248 autocorrelation function. Commonly, a three-parameter exponential function is used to 249 quantify the spatial structure of rainfall at small spatial scales (Krajewski et al., 2003; 
Villarini et al., 2008). The rainfall spatial correlation function for the radar subpixel scale

251 was estimated using the dense rain-gauge network by Peleg et al. (2013), who obtained

252 values of $C_{1}=0.923, C_{2}=3$ and $C_{3}=1$ for the three-parameter exponential function at the 253 1-min scale. In this study, a simple one-parameter exponential function can be used 254 instead of the three-parameter one, as the $C_{3}$ parameter is equal to 1 and the $C_{1}$ 255 parameter, that represents the measurement errors for each side-by-side rain-gauge, is 256 not accounted for and therefore is equal to 1 . Additional details regarding the spatial 257 structure of rainfall in the study area and a comparison between the observed and 258 modeled spatial structures are given in Appendix A and Supplementary Material S1. The 259 equations describing the generation of the Gaussian fields using Fast Fourier Transform 260 method and the calculation of the 2-D spectrum, assuming an exponential decay of the 261 autocorrelation, can be found in Paschalis et al. (2013). As in the original scheme, a lognormal function was applied to convert the 263 generated Gaussian field to the final rain field; we assume that the non-zero part of the 264 subpixel spatial rainfall distribution follows the observed lognormal distribution that is 265 recorded by the weather radar for this region (Karklinsky and Morin, 2006; Peleg and 266 Morin, 2012 and Fig. S2). The information needed for this transformation is the IMF, 267 WAR and a rainfall coefficient of variation (CV), which is a model parameter. The spatial 268 rainfall fields are correlated in time by imposing the Fourier coefficients of the Gaussian 269 fields to follow an ARMA process (i.e., temporal correlation in the Lagrangian system of 270 reference). Ideally, both the CV and ARMA parameters should be estimated using the 271 rain-gauge network, however, the rain-stations are too sparse. Therefore, the 
272 parameters were estimated from the weather radar data and scaled to higher resolution

273 as described in Supplementary Material S2.

The advection of the rain field is also simulated by the STREAP model. Here, we

275 fixed the direction component to match the westerly winds, the most frequent wind

276 direction detected for this region (Peleg and Morin, 2014), assuming that small scale

277 structure is driven by the general flow. The speed component of the advection was

278 generated using the Kappa distribution (Appendix B) based on the statistics presented

279 by Peleg and Morin (2012) for this region.

$280 \quad 3.1 .2$ Example of a simulated rain event

281 As an example of the STREAP model capability, we consider the first rain event that was 282 recorded by the dense rain-gauge network. It started on November 15 $5^{\text {th }}, 2011$ at 05:58 283 and lasted till 09:37. The total duration of the event was $220 \mathrm{~min}$, during which an 284 average of $5.6 \mathrm{~mm}$ of rainfall was accumulated according to the gauges. The maximum 285 1-min rain intensity recorded by the spatially averaged rain gauges during this event was $28684 \mathrm{~mm} \mathrm{~h}^{-1}$. The event is characteristic of an abrupt transition from no-rain to $50 \mathrm{~mm} \mathrm{~h}^{-1}$ 287 intensity in a few minutes; typical of convective cell activity for this region (Sharon and 288 Kutiel, 1986).

Three consecutive rainfall fields generated using the STREAP model for the first 290 three minutes are presented in Fig. 3. The observed IMF (simulated IMF is imposed), 291 simulated and observed max rainfall intensity (MRI) and WAR are presented in Fig. 4a. 292 The MRI is well simulated by the model. The WAR parameter is not perfectly captured 
but this is expected as there is a large uncertainty around the WAR estimation from

294 Thiessen polygons. An example of the variability of the maximum point rain intensity 295 that was "potentially" recordable by the 44,100 virtual rain-gauges for this event is 296 presented in Fig. 4b.

\subsection{IDF curves computation}

The generalized extreme value (GEV) distribution (Appendix C) is used worldwide to model rainfall extremes since theoretically it is the limit distribution of block maxima of 300 iid distributed random variables following the Gumbel, Fréchet and Weibull distributions 301 (Katz et al., 2005). Following previous rainfall frequency studies based on radar data 302 (Eldardiry et al., 2015; Marra and Morin, 2015; Overeem et al., 2009; Overeem et al., 303 2010; Paixao et al., 2015), we developed IDF curves fitting a GEV distribution to the 304 series of annual maxima. In order to keep consistency with (Marra and Morin, 2015), we 305 derive IDF curves over a single radar pixel (i.e. Domain B), corresponding to the pixel 306 overlapping with the dense rain-gauge network, focusing on $20 \mathrm{~min}, 1 \mathrm{~h}$ and $4 \mathrm{~h}$ 307 durations.

In this study IDF curves are developed from two different sources: (1) weather 309 radar (single pixel) representing the extremes of the areal mean precipitation; and (2) 310 each $10 \times 10 \mathrm{~m}^{2}$ grid cell corresponding to downscaled time series of rain intensity (i.e., 311 "virtual" rain-gauges; VG from here on) representing the rainfall variability at radar 312 subpixel scale. No condition is imposed on the time concurrency of the radar and VG 313 maxima (i.e. radar maxima are not necessarily also point maxima and vice versa). 
315 model, simulating the radar subpixel rainfall variability (domain B) for the 23-years of 316 data. We considered 100 replicates sufficient to average out the randomness of the 317 downscaling approach. For each replicate 10,000 IDF curves representing the VG are 318 calculated, i.e. one for each VG. Thus, for each duration ( $20 \mathrm{~min}, 1 \mathrm{~h}$ and $4 \mathrm{~h}$ ) a total of $3191,000,001$ IDF curves are finally available: one representing the real weather radar and $3201,000,000$ representing the virtual gauges.

\subsection{Bootstrapping}

323 A bootstrapping procedure (Efron, 1979) is applied to estimate the spatio-temporal 324 stochastic variability of the subpixel rainfall maxima. A single realization is in fact 325 insufficient to fully analyze the stochastic (natural) climate variability of the current 326 climate, especially for extremes. Bootstrapping has been applied many times in the past 327 to resample natural variability (e.g., Alexander and Arblaster, 2009; Hänggi and 328 Weingartner, 2011; Köplin et al., 2014). Bootstrapping is based on the assumption that 329 the 23-years of data are just one possible realization out of a larger population. Here, 3301,000 realizations of 23 -years each are generated out of the original sample by block 331 bootstrapping of the entire years, sampling with replacement, meaning that a specific 332 year from the sample can appear numerous times or never in each realization. Finally, 333 for each of the 1,000 bootstrapped realizations, 10,000 VG-IDF curves were computed. 
336 The STREAP model was validated using the point variability of a 1-min rain intensity as 337 observed from the 13 pairs of real rain-gauges. For simplicity, results from one 338 realization only are presented here.

The point variability of a 1-min rain intensity (Weibull distributed) was validated 340 in domain A. The rain intensity distributions of the 26 observed rain-gauges and the 341 maximum-minimum range for the rain intensity distribution that is simulated over the 34244,100 virtual rain-gauges with the STREAP model across quantiles is presented in Fig. 5. 343 For the largest part of the distribution (quantile larger than 0.3 ), the observed rain 344 intensity variability was larger than the corresponding simulated one, indicating that the 345 STREAP model slightly underestimates the rainfall variability over the domain (Fig. 5a). 346 As a matter of fact, only one or two rain-gauges are falling outside of the simulated 347 range. The part of the distribution representing the rainfall extreme in the domain 348 (0.95-0.99 quantile range), which is the main interest in this study, is well represented 349 (Fig. 5b). The only two rain-gauges which are outside the simulated range are marked in 350 Fig. $5 b$ along with their companion 1-m away rain-gauges, which are within the 351 simulated range. Ideally, the two side-by-side rain-gauges should have reproduced the 352 exact same distribution, but even after a strict QC there are small differences between 353 the two gauges that reflect in the CDFs. This implies that the true underestimation of 354 the STREAP rainfall variability is very small, if exists at all, and we conclude that the 355 simulated point rainfall variability is well within the observed rainfall variability taking 356 into account the errors in measurements of the tipping-buckets. For this reason, the 
357 following results obtained with STREAP simulations should be regarded as a very good 358 proxy of the real system.

361 The results concerning the radar subpixel variability of extreme rainfall are presented in

362 Figs. 6 and 7. Radar-IDF curves and the 5-95 quantile range of the VG-IDF representing 363 the subpixel variability as computed from STREAP are presented in the main panel of 364 Fig. 6. Cumulative distribution functions of the VG-to-radar ratio are presented for the 2, 36510 and 50 years return period (upper panel of Fig. 6) and for the $20 \mathrm{~min}, 1 \mathrm{~h}$ and $4 \mathrm{~h}$ 366 durations (right panel of the Fig. 6). In addition, the 5-95 quantile range of the ratio of 367 the VG-to-radar IDF value for a given duration and for a given return period is presented 368 in the lower panel of Fig. 6. Two scores are calculated for each of the cumulative 369 distribution functions: (1) percentile of the transition point from cumulative 370 underestimation to overestimation of the local extreme rainfall compared to the areal 371 extreme rainfall (i.e., VG/radar equals one); and (2) interquartile range (IQR), 372 representing the scatter of the distribution for the $25-75$ quantile.

373 The inflection point is found to be positively dependent on the duration, 374 increasing from a percentile value of 0.23 for the $20 \mathrm{~min}$ to 0.32 for the $4 \mathrm{~h}$ durations. A 375 positive dependency is also noticed between the inflection point and the return period. 376 Percentile values of $0.24,0.28$ and 0.37 are computed for the 2,10 and 50 years return 377 periods, respectively. Those results indicate that the extreme mean areal rainfall 
intensities tend to underestimate the extreme point rainfall intensities within the

379 subpixel area. This is the case for all durations and for all return periods and it is more 380 evident for the lower return periods and shorter durations. In other words, comparing a 381 randomly selected single gauge-IDF curve to a radar-IDF curve, one should expect the 382 gauge-IDF to be higher than the radar-IDF in most of the cases. For example, for a 2-year 383 return period there is a $76 \%$ chance for an IDF curve developed from a single rain-gauge 384 to overestimate the radar-IDF. Overestimation (Eldardiry et al., 2015), underestimation 385 (Marra and Morin, 2015) or "reasonable agreement" (Overeem et al., 2009; Paixao et 386 al., 2015) relationships between a gauge-IDF and a radar-IDF are therefore all possible 387 outcomes. The sensitivity to the selection of a rain-gauge or to its random positioning is 388 quite large due to the considerable spatial variability of extreme rainfall at the subpixel 389 scale. Further amelioration of radar QPE and reducing radar-gauge biases (Eldardiry et 390 al., 2015; Marra and Morin, 2015) will likely improve the relationships between the 391 radar-IDF and a single gauge-IDF, but of course will not eliminate the uncertainty due to 392 the spatial (subpixel) rainfall variability. A negative dependency is found between the IQR and the duration. The IQR 394 values decreases from 0.081 to 0.048 , comparing the $20 \mathrm{~min}$ and the $4 \mathrm{~h}$ durations. 395 Moreover, a positive dependency between the IQR and the return period is found. The 396 IQR values increase from 0.066 to 0.087 , comparing the 2 and 50 years return periods. 397 The IQR score directly reflects the subpixel scatter in extreme rainfall; the higher the IQR 398 is, the higher the variability of extreme rainfall is. For example, the tails of the CDF for 399 the 50-years return period $(\mathrm{IQR}=0.087)$ are much wider than the tails of the 2-years 
return period (IQR=0.066), thus the probability of a randomly selected gauge-IDF to

401 over- or under-estimate the radar-IDF by $20 \%$ is much larger for the 50 -years return

402 period. In general, the subpixel spatial scatter of extremes was found to be larger for 403 long return periods and for short durations.

The VG-IDF curves computed taking into account the stochastic (natural) climate 405 variability are presented in Fig. 7. This figure contains the VG-IDF curves that were 406 calculated from 100 realizations based on the annual maxima downscaled with STREAP 407 for the 23-years radar data, as in Fig. 6 (spatial stochastic variability from here on), and 408 the 1,000 realizations generated from the bootstrapped data (spatio-temporal 409 stochastic variability from here on). The rationale is to compare the subpixel spatial 410 stochastic variability with the spatio-temporal stochastic variability related to the fact 411 that IDF curves estimated from a single climatic realization, even of 23 years, are 412 expected to be relatively uncertain.

As in Fig. 6, the 5-95 quantile range of the subpixel variability of rainfall 414 extremes is presented for both cases (Fig. 7b). The VG 5-95 quantile range derived 415 from the spatio-temporal stochastic variability is always larger than the corresponding 416 quantile range of the spatial stochastic variability, as the spatial stochastic variability 417 represents only part of the stochastic (natural) climate variability. A simple way to 418 quantify how well the extreme subpixel rainfall variability is represented by the spatial 419 stochastic variability is by comparing the contribution of the extreme rainfall variability 420 derived from the spatial stochastic variability to the one derived from the spatio- 
421 temporal stochastic variability. This was done using a spatial-to-temporal ratio score 422 (STR):

$423 \quad \operatorname{STR}_{R P, D}=\left(\frac{q_{0.95}^{S}-q_{0.05}^{S}}{q_{0.95}^{T}-q_{0.05}^{T}}\right)_{R P, D}$

424 The STR is computed from IDF values for each return period $(R P)$ and duration $(D)$ by 425 finding the ratio between the range of the VG 5-95 quantile generated using the 426 spatial stochastic variability $\left(q_{0.95}^{S}-q_{0.05}^{S}\right)$ and the same range derived from the spatio427 temporal stochastic variability $\left(q_{0.95}^{T}-q_{0.05}^{T}\right)$. The STR score (an example relative to the 20 min duration is presented in Fig. 7a) 429 is found to decrease for higher return periods. This is observed for all durations. The STR 430 decrease starts around the 6 year return period, which is about one quarter of the 431 sample size (23 years). Up to this point the spatio-temporal stochastic variability of 432 extreme rainfall is well represented by the spatial stochastic variability (STR values of $433 \quad 0.95-0.99$ are computed for all durations). For the 30 and 50 year return period STR 434 values of $0.74,0.71$ and 0.77 , and $0.67,0.63$ and 0.71 are found for the $20 \mathrm{~min}, 1 \mathrm{~h}$ and $4354 \mathrm{~h}$ durations (respectively). The lower estimates of the subpixel extreme rainfall 436 intensity (0.05 quantile) were very similar when the spatial and spatio-temporal 437 stochastic variability were compared (Fig. 7b). The difference between samples was 438 expressed mainly by the upper (0.95) quantile. For example, for the 50 year return 439 period a difference of $31.8,11.4$ and $1.8 \mathrm{~mm} \mathrm{~h}^{-1}$ was found between the spatial and the 440 spatio-temporal stochastic variability for the $20 \mathrm{~min}, 1 \mathrm{~h}$ and $4 \mathrm{~h}$ durations 
441 (respectively). This implies that the role of stochastic (natural) climate variability is very

442 important and must be considered especially for long return periods and short

443 durations. The good correspondence between spatial and spatio-temporal stochastic

444 variability for short return periods suggests that a dense rain-gauge network can

445 eventually substitute a long gauge record to account for the radar subpixel variability of

446 rainfall extremes. In other words, for "ordinary" extremes (i.e., short return periods) the

447 gauge-to-gauge variability in a given radar pixel is not much dissimilar from the year-to-

448 year variability in a given long-recording gauge. However, for "infrequent" extremes

449 (i.e., long return periods) a denser spatial sampling cannot substitute for a long

450 observational period because these extreme rain intensities are likely related to very

451 specific weather patterns occurring so rarely that only a long-continuous monitoring can

452 detect their occurrence.

From the above results we can conclude that the subpixel variability of extreme

454 rainfall is an important feature when estimating rainfall extremes using remote sensing

455 instruments such as weather radars. In the presented case study, for a 50-year return

456 period and a 20 min duration, an extreme rainfall intensity of $150.7 \mathrm{~mm} \mathrm{~h}^{-1}$ would be

457 computed based on the radar-IDF only. However, a range of $133.9-194.6 \mathrm{~mm} \mathrm{~h}^{-1}$

458 represents the actual variability of extreme rainfall that is expected in any specific

459 location within the radar pixel. This range is even larger $\left(133.9-226.5 \mathrm{~mm} \mathrm{~h}^{-1}\right)$ when

460 taking the stochastic climate variability into account.

Explicitly addressing the extreme rainfall variability over a small spatial scale is

462 important for local impact studies. This may include studies for designing of urban 
drainage systems that require rainfall in a higher spatial resolution than recorded by a

464 common C-band radar (Gires et al., 2012; Gires et al., 2013; Gregersen et al., 2013;

465 Ochoa-Rodriguez et al., 2015; Willems et al., 2012). Drainage system effectiveness is 466 evaluated to face extreme rainfall events using "design storms" that are typically based 467 on gauge-IDF curve data derived from a nearby location (for an extensive review see 468 Marsalek and Watt (1984) and Watt and Marsalek, 2013). Short-duration extremes are 469 often linked to small-scale convective events (García-Bartual and Schneider, 2001) that 470 are difficult to capture by a single or even with a relatively dense rain-gauge network 471 (Marra et al., 2014; Nikolopoulos et al., 2015; Nikolopoulos et al., 2014) but can be 472 captured by a weather radar (Peleg and Morin, 2012). With this analysis, we show that 473 an ensemble of design storms representing the variability of short-duration extreme 474 rainfall over a potential urban catchment can be derived by analyzing the overlying 475 radar pixels (using similar methods and tools as presented here) and using stochastic 476 rainfall generators such as STREAP to quantify uncertainties. Such a procedure will likely 477 lead to a better assessment of the drainage system effectiveness.

480 In this study we explicitly simulated the variability of extreme rainfall intensity at the 481 radar subpixel scale by applying the stochastic rainfall generator STREAP to simulate rain 482 fields with an unprecedented high spatial and temporal resolution (i.e., $10 \times 10 \mathrm{~m}^{2}$ and 1 $483 \mathrm{~min})$. The model was tested using a dense network of rain-gauges. IDF curves were 
computed using the radar data and the downscaled values in order to compare rainfall extremes at two different scales: the radar pixel scale $\left(1 \mathrm{~km}^{2}\right)$ and the point scale (virtual rain-gauges represented by the $10 \times 10 \mathrm{~m}^{2}$ gridded downscaled data). The uncertainty in the variability of extreme rainfall has been fully evaluated using a bootstrapping technique to address the space-time stochastic variability.

The key findings of this study are:

- Extreme rainfall derived from radar underestimates extreme rainfall computed for point locations within the radar pixel for most of the pixel area. On average, about $70 \%$ of the area within the radar pixel is likely underestimated using radar IDFs. This underestimation is smaller for longer return periods.

- The subpixel variability of extreme rainfall is found to increase with longer return periods and shorter durations. The maximum error in computing extreme rainfall for a point location from radar for a return period of 2 years and a duration of 4 h can be of $10 \%$; this error increases to $30 \%$ for 50 years return period and 20 min duration.

- The uncertainty in computing subpixel variability of extreme rainfall increases when natural climate variability is taken into account. For a 23 -years record, we found that estimates of extreme rainfall variability for return period of 6 years or less (1/4 of the radar sample) are marginally affected by natural climate variability (spatial and spatio-temporal stochasticity are comparable). However, for longer return periods, natural climate variability can increase uncertainty by up to $16 \%$ of the estimate. 
507 shortcoming, as the extreme rainfall in a given point within the radar pixel is on average

508 at least $10 \%$ larger than the extreme rainfall estimated using the weather radar. This 509 effect can be amplified if natural climate variability is properly accounted for. We

510 therefore suggest that IDF curves directly derived from radar observations should be

511 used carefully since they do not include important sources of uncertainty, which must

512 be considered for applications requiring rainfall extremes at scales finer than the ones

513 supplied by the weather radar. In this study, we show that this can be achieved by

514 means of stochastic rainfall generators such as STREAP, which are useful tools to bridge 515 the gap between the radar and point scales and also to explore nature climate 516 variability.

\section{Acknowledgments}

519 The authors thank Kibbutz Galed for their valuable assistance and cooperation in setting

520 and maintaining the dense rain-gauge network. Radar data were provided by E.M.S.

521 (Mekorot Company). We thank the two reviewers (Geoffrey Pegram and a second 522 anonymous reviewer) and to András Bárdossy, the editor-in-Chief, for their significantly 523 contribution to the quality of the paper. This research was partially supported by the

524 Swiss Competence Center for Energy Research - Supply of Electricity (SCCER-SoE, 525 http://sccer-soe.ch/). 
528 The three-parameter exponential function for a spatial correlation $\rho$ at a separation 529 distance $h$ is described as:

530

$$
\rho(h)=C_{1} \cdot \exp \left[-\left(\frac{h}{C_{2}}\right)^{C_{3}}\right]
$$

531 where $C_{1}$ represents the zero-distance correlation, $C_{2}$ is the correlation distance and $532 C_{3}$ is the shape factor. The spatial correlation function for the dense rain-gauge 533 network in Israel was studied by Peleg et al. (2013) and values of $C_{1}=0.923, C_{2}=3$ and $534 C_{3}=1$ were computed for the 1-min scale. In this study, a simple one-parameter 535 exponential function can be used instead of the three-parameter exponential function, 536 as the $C_{3}$ parameter is equal to 1 and the $C_{1}$ parameter, that represents the 537 measurement errors for each side-by-side rain-gauge (see Peleg et al. (2013) for 538 additional information), is not accounted for and therefore can be also assumed to be 539 equal to 1 . The simulated correlation functions are not static but for each storm a new 540 stochastic Gaussian field is generated with a different correlation. A comparison 541 between the observed correlation function and 1,000 simulated correlograms, which 542 were generated after calibration, are presented in Fig. A.1. The underestimation of the 543 simulated spatial correlation for the $0-200 \mathrm{~m}$ distance range is due to the fact that we 544 do not want to reproduce the correlation smaller than one at distance zero, which is 545 most likely an artifact of the measurements error $\left(C_{1}\right)$. The simulated spatial correlation 546 correspond to mean ( \pm standard deviation) value of $C_{2}=2.48( \pm 0.31)$. The generated 
547 fields result in a slightly faster decay than the observed spatial correlation; for example,

548 for the $2-\mathrm{km}$ distance the mean observed and simulated values were $\rho_{\text {obs }}(2)=0.47$ and $549 \rho_{\text {sim }}(2)=0.44$, respectively. The rainfall spatial correlation function was calculated using 550 the rainfall time series that was recorded by the stations. The Moran's I and Geary's C 551 indices (see Supplementary Material S1) were applied to verify that the spatial 552 correlation function is not influenced by the instantaneous rainfall intensity. By 553 estimating the mean of both indices versus the instantaneous maximum rainfall 554 intensity measured for 1 -min time intervals $(C \approx 0.6, I \approx 0)$, it was determined that no 555 dependence exists between the instantaneous maximum rainfall intensity and the 556 spatial structure of the rainfall.

\section{Appendix B - Kappa distribution}

559 The 4-parameter Kappa (KAP) distribution was presented by Hosking (1994). It is a 560 generalization of many other distributions and includes as special cases the Generalized 561 Logistic, GEV, and Generalized Pareto distributions. The KAP cumulative distribution 562 function $F(U ; \xi, \alpha, k, h)$ are:

$563 \quad F(U ; \xi, \alpha, k, h)=\left\{1-h[1-k(U-\xi) / \alpha]^{1 / k}\right\}^{1 / h}$

564 where $U$ is the wind speed, $\xi$ is the location parameter, $\alpha$ is the scale parameter, and $k$ 565 and $h$ are the two shape parameter of the distribution. The distribution parameters are 566 estimated using L-moments following the method suggested by Hosking (Hosking and 
567 Wallis, 1993; Hosking and Wallis, 1995; Hosking and Wallis, 2005). The KAP distribution 568 was generally found to provide a good fit to the wind speed in comparison to other 569 distributions (Morgan et al., 2011; Ouarda et al., 2015).

\section{Appendix C - GEV distribution}

572 The Generalized Extreme Values (GEV) distribution combines the Gumbel, Fréchet and

573 Weibull asymptotic extreme value distributions (Types I, II and III, respectively) into a 574 single one. The GEV cumulative distribution function $F(U ; \mu, \sigma, \kappa)$ was given by 575 Jenkinson (1955):

576

$$
\left\{\begin{array}{l}
F(U ; \mu, \sigma, \kappa)=\exp \left\{-\left[1-\frac{\kappa}{\sigma}(U-\mu)\right]^{\frac{1}{\kappa}}\right\} \text { for } \kappa \neq 0 \\
F(U ; \mu, \sigma, \kappa)=\exp \left\{-\exp \left[-\frac{1}{\sigma}(U-\mu)\right]\right\} \text { for } \kappa=0
\end{array}\right.
$$

577 where $U$ is the rainfall intensity, $\mu$ is the location parameter, $\sigma$ is the scale parameter 578 and $\mathrm{K}$ is the shape parameter of the distribution. The GEV distribution parameters were 579 estimated using maximum likelihood method. 
583 Alexander, L.V., Arblaster, J.M., 2009. Assessing trends in observed and modelled 584 climate extremes over Australia in relation to future projections. International Journal of Climatology, 29(3): 417-435. DOI:10.1002/joc.1730

Allen, R.J., DeGaetano, A.T., 2005. Considerations for the use of radar-derived precipitation estimates in determining return intervals for extreme areal precipitation amounts. Journal of Hydrology, 315(1-4): 203-219. DOI:http://dx.doi.org/10.1016/j.jhydrol.2005.03.028

590

Bell, T.L., 1987. A space-time stochastic model of rainfall for satellite remote-sensing studies. Journal of Geophysical Research: Atmospheres, 92(D8): 9631-9643. DOI:10.1029/JD092iD08p09631

Ciach, G.J., Krajewski, W.F., 1999. On the estimation of radar rainfall error variance. $\begin{array}{llll}\text { Advances } \quad \text { in } \quad \text { 22(6): } & \text { 585-595. }\end{array}$ DOI:http://dx.doi.org/10.1016/S0309-1708(98)00043-8

Ciach, G.J., Krajewski, W.F., 2006. Analysis and modeling of spatial correlation structure in small-scale rainfall in Central Oklahoma. Advances in Water Resources, 29(10): 1450-1463. DOI:http://dx.doi.org/10.1016/j.advwatres.2005.11.003

Coles, S., Bawa, J., Trenner, L., Dorazio, P., 2001. An introduction to statistical modeling of extreme values, 208. Springer.

Durrans, S., Julian, L., Yekta, M., 2002. Estimation of Depth-Area Relationships using Radar-Rainfall Data. Journal of Hydrologic Engineering, 7(5): 356-367. DOI:10.1061/(ASCE)1084-0699(2002)7:5(356) 
604

605

606

607

608

609

610

Efron, B., 1979. Bootstrap Methods: Another Look at the Jackknife. The Annals of Statistics, 7(1): 1-26.

Eldardiry, H., Habib, E., Zhang, Y., 2015. On the use of radar-based quantitative precipitation estimates for precipitation frequency analysis. Journal of Hydrology, 531,

Part

2: 441-453. DOI:http://dx.doi.org/10.1016/j.jhydrol.2015.05.016

Fiener, P., Auerswald, K., 2009. Spatial variability of rainfall on a sub-kilometre scale. Earth Surface Processes and Landforms, 34(6): 848-859. DOI:10.1002/esp.1779

García-Bartual, R., Schneider, M., 2001. Estimating maximum expected short-duration rainfall intensities from extreme convective storms. Physics and Chemistry of the Earth, Part B: Hydrology, Oceans and Atmosphere, 26(9): 675-681. DOI:http://dx.doi.org/10.1016/S1464-1909(01)00068-5

Gires, A. et al., 2012. Quantifying the impact of small scale unmeasured rainfall variability on urban runoff through multifractal downscaling: A case study. Journal of Hydrology, 442-443:

117-128. DOI:http://dx.doi.org/10.1016/j.jhydrol.2012.04.005

Gires, A., Tchiguirinskaia, I., Schertzer, D., Lovejoy, S., 2013. Multifractal analysis of a semi-distributed urban hydrological model. Urban Water Journal, 10(3): 195-208. DOI:10.1080/1573062X.2012.716447

Gregersen, I. et al., 2013. Assessing future climatic changes of rainfall extremes at small spatio-temporal scales. Climatic Change, 118(3-4): 783-797. DOI:10.1007/s10584-012-0669-0 
Hänggi, P., Weingartner, R., 2011. Inter-annual variability of runoff and climate within the Upper Rhine River basin, 1808-2007. Hydrological Sciences Journal, 56(1): 34-50. DOI:10.1080/02626667.2010.536549

Hosking, J.R.M., 1994. The four-parameter kappa distribution. IBM J. Res. Dev., 38(3): 251-258. DOI:10.1147/rd.383.0251

Hosking, J.R.M., Wallis, J.R., 1993. Some statistics useful in regional frequency analysis. Water Resources Research, 29(2): 271-281. DOI:10.1029/92WR01980

Hosking, J.R.M., Wallis, J.R., 1995. Correction to "Some Statistics Useful in Regional Frequency Analysis". Water Resources Research, 31(1): 251-251. DOI:10.1029/94WR02510

Hosking, J.R.M., Wallis, J.R., 2005. Regional frequency analysis: an approach based on Lmoments. Cambridge University Press.

Jaffrain, J., Berne, A., 2012. Quantification of the Small-Scale Spatial Structure of the Raindrop Size Distribution from a Network of Disdrometers. Journal of Applied Meteorology and Climatology, 51(5): 941-953. DOI:10.1175/JAMC-D-11-0136.1

Jenkinson, A.F., 1955. The frequency distribution of the annual maximum (or minimum) values of meteorological elements. Quarterly Journal of the Royal Meteorological Society, 81(348): 158-171. DOI:10.1002/qj.49708134804

Jensen, N.E., Pedersen, L., 2005. Spatial variability of rainfall: Variations within a single radar pixel. Atmospheric Research, 77(1-4): 269-277. DOI:http://dx.doi.org/10.1016/j.atmosres.2004.10.029 
Karklinsky, M., Morin, E., 2006. Spatial characteristics of radar-derived convective rain cells over southern Israel. Meteorologische Zeitschrift, 15(5): 513-520. DOI:10.1127/0941-2948/2006/0153

Katz, R.W., Brush, G.S., Parlange, M.B., 2005. STATISTICS OF EXTREMES: MODELING ECOLOGICAL DISTURBANCES. Ecology, 86(5): 1124-1134. DOI:10.1890/04-0606

Katz, R.W., Parlange, M.B., Naveau, P., 2002. Statistics of extremes in hydrology. Advances in Water Resources, 25(8-12): 1287-1304. DOI:http://dx.doi.org/10.1016/S0309-1708(02)00056-8

Köplin, N., Rößler, O., Schädler, B., Weingartner, R., 2014. Robust estimates of climateinduced hydrological change in a temperate mountainous region. Climatic Change, 122(1-2): 171-184. DOI:10.1007/s10584-013-1015-x

Koutsoyiannis, D., Kozonis, D., Manetas, A., 1998. A mathematical framework for studying rainfall intensity-duration-frequency relationships. Journal of Hydrology, 206(1-2): 118-135. DOI:http://dx.doi.org/10.1016/S00221694(98)00097-3

Krajewski, W.F., Ciach, G.J., Habib, E., 2003. An analysis of small-scale rainfall variability in different climatic regimes. Hydrological Sciences Journal, 48(2): 151-162. DOI:10.1623/hysj.48.2.151.44694

Krajewski, W.F., Ciach, G.J., McCollum, J.R., Bacotiu, C., 2000. Initial Validation of the Global Precipitation Climatology Project Monthly Rainfall over the United States. Journal of Applied Meteorology, 39(7): 1071-1086. DOI:10.1175/15200450(2000)039<1071:IVOTGP>2.0.CO;2 
669

670

Krajewski, W.F., Villarini, G., Smith, J.A., 2010. RADAR-Rainfall Uncertainties. Bulletin of the American Meteorological Society, 91(1): 87-94. DOI:10.1175/2009BAMS2747.1

Kundu, P.K., Bell, T.L., 2003. A stochastic model of space-time variability of mesoscale rainfall: Statistics of spatial averages. Water Resources Research, 39(12): n/a-n/a. DOI:10.1029/2002WR001802

Lombardo, F., Napolitano, F., Russo, F., 2006. On the use of radar reflectivity for estimation of the areal reduction factor. Nat. Hazards Earth Syst. Sci., 6(3): 377386. DOI:10.5194/nhess-6-377-2006

Marra, F., Morin, E., 2015. Use of radar QPE for the derivation of Intensity-DurationFrequency curves in a range of climatic regimes. Journal of Hydrology, 531, Part 2: 427-440. DOI:http://dx.doi.org/10.1016/j.jhydrol.2015.08.064

Marra, F., Nikolopoulos, E.I., Creutin, J.D., Borga, M., 2014. Radar rainfall estimation for the identification of debris-flow occurrence thresholds. Journal of Hydrology, 519, Part B: 1607-1619. DOI:http://dx.doi.org/10.1016/j.jhydrol.2014.09.039

Marsalek, J., Watt, W.E., 1984. Design storms for urban drainage design. Canadian Journal of Civil Engineering, 11(3): 574-584. DOI:10.1139/I84-075

Morgan, E.C., Lackner, M., Vogel, R.M., Baise, L.G., 2011. Probability distributions for offshore wind speeds. Energy Conversion and Management, 52(1): 15-26. DOI:http://dx.doi.org/10.1016/j.enconman.2010.06.015 
Morin, E., Enzel, Y., Shamir, U., Garti, R., 2001. The characteristic time scale for basin hydrological response using radar data. Journal of Hydrology, 252(1-4): 85-99. DOI:http://dx.doi.org/10.1016/S0022-1694(01)00451-6

Morin, E., Gabella, M., 2007. Radar-based quantitative precipitation estimation over Mediterranean and dry climate regimes. Journal of Geophysical Research: Atmospheres, 112(D20): n/a-n/a. DOI:10.1029/2006JD008206

Morrissey, M.L., Maliekal, J.A., Greene, J.S., Wang, J., 1995. The Uncertainty of Simple Spatial Averages Using Rain Gauge Networks. Water Resources Research, 31(8): 2011-2017. DOI:10.1029/95WR01232

Nikolopoulos, E.I., Borga, M., Creutin, J.D., Marra, F., 2015. Estimation of debris flow triggering rainfall: Influence of rain gauge density and interpolation methods. Geomorphology, 243: 40-50. DOI:http://dx.doi.org/10.1016/j.geomorph.2015.04.028

Nikolopoulos, E.I. et al., 2014. Impact of uncertainty in rainfall estimation on the identification of rainfall thresholds for debris flow occurrence. Geomorphology, 221: 286-297. DOI:http://dx.doi.org/10.1016/j.geomorph.2014.06.015

Ochoa-Rodriguez, S. et al., 2015. Impact of spatial and temporal resolution of rainfall inputs on urban hydrodynamic modelling outputs: A multi-catchment investigation. Journal of Hydrology, 531, Part 2: 389-407. DOI:http://dx.doi.org/10.1016/j.jhydrol.2015.05.035 
Ouarda, T.B.M.J. et al., 2015. Probability distributions of wind speed in the UAE. Energy Conversion and Management, 93: 414-434. DOI:http://dx.doi.org/10.1016/j.enconman.2015.01.036

Overeem, A., Buishand, T.A., Holleman, I., 2009. Extreme rainfall analysis and estimation of depth-duration-frequency curves using weather radar. Water Resources Research, 45(10): n/a-n/a. DOI:10.1029/2009WR007869

Overeem, A., Buishand, T.A., Holleman, I., Uijlenhoet, R., 2010. Extreme value modeling of areal rainfall from weather radar. Water Resources Research, 46(9): n/a-n/a. DOI:10.1029/2009WR008517

Paixao, E. et al., 2015. An integrated approach for identifying homogeneous regions of extreme rainfall events and estimating IDF curves in Southern Ontario, Canada: Incorporating radar observations. Journal of Hydrology, 528: 734-750. DOI:http://dx.doi.org/10.1016/j.jhydrol.2015.06.015

Paschalis, A., 2013. Modelling the space-time structure of precipitation and its impact on basin response, Zürich : ETH, 1 Band pp. DOI:10.3929/ethz-a-009917135

Paschalis, A., Fatichi, S., Molnar, P., Rimkus, S., Burlando, P., 2014. On the effects of small scale space-time variability of rainfall on basin flood response. Journal of Hydrology, 514: 313-327. DOI:http://dx.doi.org/10.1016/j.jhydrol.2014.04.014

Paschalis, A., Molnar, P., Fatichi, S., Burlando, P., 2013. A stochastic model for highresolution space-time precipitation simulation. Water Resources Research, 49(12): 8400-8417. DOI:10.1002/2013WR014437 
Pedersen, L., Jensen, N.E., Christensen, L.E., Madsen, H., 2010. Quantification of the spatial variability of rainfall based on a dense network of rain gauges. Atmospheric Research, 95(4):

441-454. DOI:http://dx.doi.org/10.1016/j.atmosres.2009.11.007

Pegram, G.G.S., Clothier, A.N., 2001a. Downscaling rainfields in space and time, using the String of Beads model in time series mode. Hydrol. Earth Syst. Sci., 5(2): 175186. DOI:10.5194/hess-5-175-2001

Pegram, G.G.S., Clothier, A.N., 2001b. High resolution space-time modelling of rainfall: the "String of Beads" model. Journal of Hydrology, 241(1-2): 26-41. DOI:http://dx.doi.org/10.1016/S0022-1694(00)00373-5

Peleg, N., Ben-Asher, M., Morin, E., 2013. Radar subpixel-scale rainfall variability and uncertainty: lessons learned from observations of a dense rain-gauge network. Hydrol. Earth Syst. Sci., 17(6): 2195-2208. DOI:10.5194/hess-17-2195-2013

Peleg, N., Morin, E., 2012. Convective rain cells: Radar-derived spatiotemporal characteristics and synoptic patterns over the eastern Mediterranean. Journal of Geophysical Research: Atmospheres, 117(D15): n/a-n/a. DOI:10.1029/2011JD017353

Peleg, N., Morin, E., 2014. Stochastic convective rain-field simulation using a highresolution synoptically conditioned weather generator (HiReS-WG). Water Resources Research, 50(3): 2124-2139. DOI:10.1002/2013WR014836 
Rodriguez-Iturbe, I., Mejía, J.M., 1974a. On the transformation of point rainfall to areal rainfall. Water Resources Research, 10(4): 729-735. DOI:10.1029/WR010i004p00729

Rodríguez-Iturbe, I., Mejía, J.M., 1974b. The design of rainfall networks in time and $\begin{array}{lll}\text { space. Water } & \text { Resources } & \text { Research, }\end{array}$ DOI:10.1029/WR010i004p00713

Rozalis, S., Morin, E., Yair, Y., Price, C., 2010. Flash flood prediction using an uncalibrated hydrological model and radar rainfall data in a Mediterranean watershed under changing hydrological conditions. Journal of Hydrology, 394(1-2): 245-255. DOI:http://dx.doi.org/10.1016/j.jhydrol.2010.03.021

Schleiss, M., Jaffrain, J., Berne, A., 2011. Stochastic Simulation of Intermittent DSD Fields in Time. Journal of Hydrometeorology, 13(2): 621-637. DOI:10.1175/JHM-D-11018.1

Schleiss, M.A., Berne, A., Uijlenhoet, R., 2009. Geostatistical simulation of twodimensional fields of raindrop size distributions at the meso- $\nu$ scale. Water Resources Research, 45(7): n/a-n/a. DOI:10.1029/2008WR007545

Sharon, D., Kutiel, H., 1986. The distribution of rainfall intensity in Israel, its regional and seasonal variations and its climatological evaluation. Journal of Climatology, 6(3): 277-291. DOI:10.1002/joc.3370060304

Sivapalan, M., Blöschl, G., 1998. Transformation of point rainfall to areal rainfall: Intensity-duration-frequency curves. Journal of Hydrology, 204(1-4): 150-167. DOI:http://dx.doi.org/10.1016/S0022-1694(97)00117-0 
772 Svensson, C., Jones, D.A., 2010. Review of methods for deriving areal reduction factors. Journal of Flood Risk Management, 3(3): 232-245. DOI:10.1111/j.1753318X.2010.01075.x

775

Veneziano, D., Langousis, A., 2005. The areal reduction factor: A multifractal analysis. Water Resources Research, 41(7): n/a-n/a. DOI:10.1029/2004WR003765

Villarini, G., Mandapaka, P.V., Krajewski, W.F., Moore, R.J., 2008. Rainfall and sampling uncertainties: A rain gauge perspective. Journal of Geophysical Research: Atmospheres, 113(D11): n/a-n/a. DOI:10.1029/2007JD009214

Watt, E., Marsalek, J., 2013. Critical review of the evolution of the design storm event concept. Canadian Journal of Civil Engineering, 40(2): 105-113. DOI:10.1139/cjce2011-0594

Willems, P., Arnbjerg-Nielsen, K., Olsson, J., Nguyen, V.T.V., 2012. Climate change impact assessment on urban rainfall extremes and urban drainage: Methods and shortcomings. Atmospheric Research, 103: 106-118. DOI:http://dx.doi.org/10.1016/j.atmosres.2011.04.003 
790 Fig 1. Map of the $2100 \mathrm{~m} \times 2100 \mathrm{~m}$ domain of the dense rain-gauge network deployed in 791 northern Israel (Domain A). The 13 locations where two side-by-side rain gauges are 792 installed (blue triangles) and the $210 \times 210$ grid are presented in the main frame; a 793 magnification of the grid (pixel size of $10 \mathrm{~m} \times 10 \mathrm{~m}$ ) is presented in the yellow circle. Red 794 area represents the location of the $1000 \mathrm{~m} \times 1000 \mathrm{~m}$ domain (Domain B). A black star 795 marks the study area's location in Israel.

796 Fig 2. A schematic diagram of the methods used to estimate the subpixel extreme 797 rainfall variability. (1) Domain $A$ is used for the calibration and validation of the STREAP 798 model. (2) Domain B is used for the downscaling of rainfall from the radar pixel scale to 799 nearly point scale. (3) The downscaled point rainfall time series are used to compute the 800 IDF curves.

801 Fig 3. Three consecutive rainfall fields generated using the STREAP model. The field grid 802 is composed of $210 \times 210$ pixels, the dimension of each pixel is $10 \mathrm{~m} \times 10 \mathrm{~m}$. The fields represent the first 3 time steps of the rainfall event presented in Fig. 4.

804 Fig 4. Example of a rainfall event. (a) The max rainfall intensity (MRI) and the wet area 805 ratio (WAR) simulated by STREAP (red lines) are compared with observed data (grey 806 area); the mean areal rainfall intensity (IMF, red bars) is also shown. (b) The histogram 807 of the simulated maximum rain intensity, as recorded by each grid point (i.e. 44,100 808 virtual rain gauges) for the given event is presented. 
Fig 5. An inverse cumulative distribution function of the rain intensity that was recorded

810 and simulated over domain A. The grey lines represent the 26 rain-gauges of the dense

811 rain-gauge network. Yellow area marks the maximum and minimum rain intensity range

812 of the 44,100 virtual rain-gauges that were simulated using one realization of the

813 STREAP model. The $0.01-1$ quantile is presented in (a) and the $95-99$ quantile range is

814 zoomed in (b). The blue lines in (b) represent the inverse-CDF of the rain intensity that

815 were recorded by two rain-gauges located in the same station (separated by $1 \mathrm{~m}$

816 distance), representing the observed maximum rain intensity. The red lines in (b)

817 represent the same, but for the minimum rain intensity range.

818 Fig 6. Analysis of IDF curve for a given radar pixel. The return periods were calculated

819 using the GEV distribution from a 23-years dataset derived from the weather radar for

820 durations of $20 \mathrm{~min}, 1 \mathrm{~h}$ and $4 \mathrm{~h}$ (purple, orange and green line, respectively). Grey areas

821 represent the 5-95 quantile range of virtual rain-gauges for each duration from 100

822 realizations that were generated using the STREAP model. Cumulative distribution

823 functions of the simulated VG-to-radar ratio for the 100 realizations are presented for

824 the 2, 10 and 50 years return period (above panel) and for the $20 \mathrm{~min}, 1 \mathrm{~h}$ and $4 \mathrm{~h}$

825 durations (right panel). Red area represents gauge overestimation and blue area

826 represents gauge underestimation in comparison with the radar. Orange arrow points to

827 the percentile characterizing the inflection between the under- and over-estimation.

828 The interquartile range (IQR) represents the scatter of the distribution for the 25-75

829 quantile. The simulated VG-to-radar ratio for a given return period and for a given

830 duration is also presented in the lower panel of the plot. 
831 Fig 7. The subpixel variability of extreme rainfall for 100 realizations based on the 832 STREAP downscaled annual maxima (spatial stochastic variability) and for 1,000 833 realizations bootstrapped to account for stochastic natural climate variability (spatio834 temporal stochastic variability). (a) The spatial-to-temporal ratio score (STR) for 20 min 835 duration and (b) IDF curves for the spatial (grey area) and for the spatio-temporal 836 stochastic variability (green area) are shown.

837 Fig A.1. The spatial correlation function ( $\rho)$ as a function of distance for 1-min temporal 838 scale. Observed line (dashed red) was calculated using the dense rain-gauge network 839 data (Peleg et al., 2013). Simulated lines (black) were calculated from 1,000 fields that 840 were generated with the STREAP model. 
Figure 1

Click here to download high resolution image

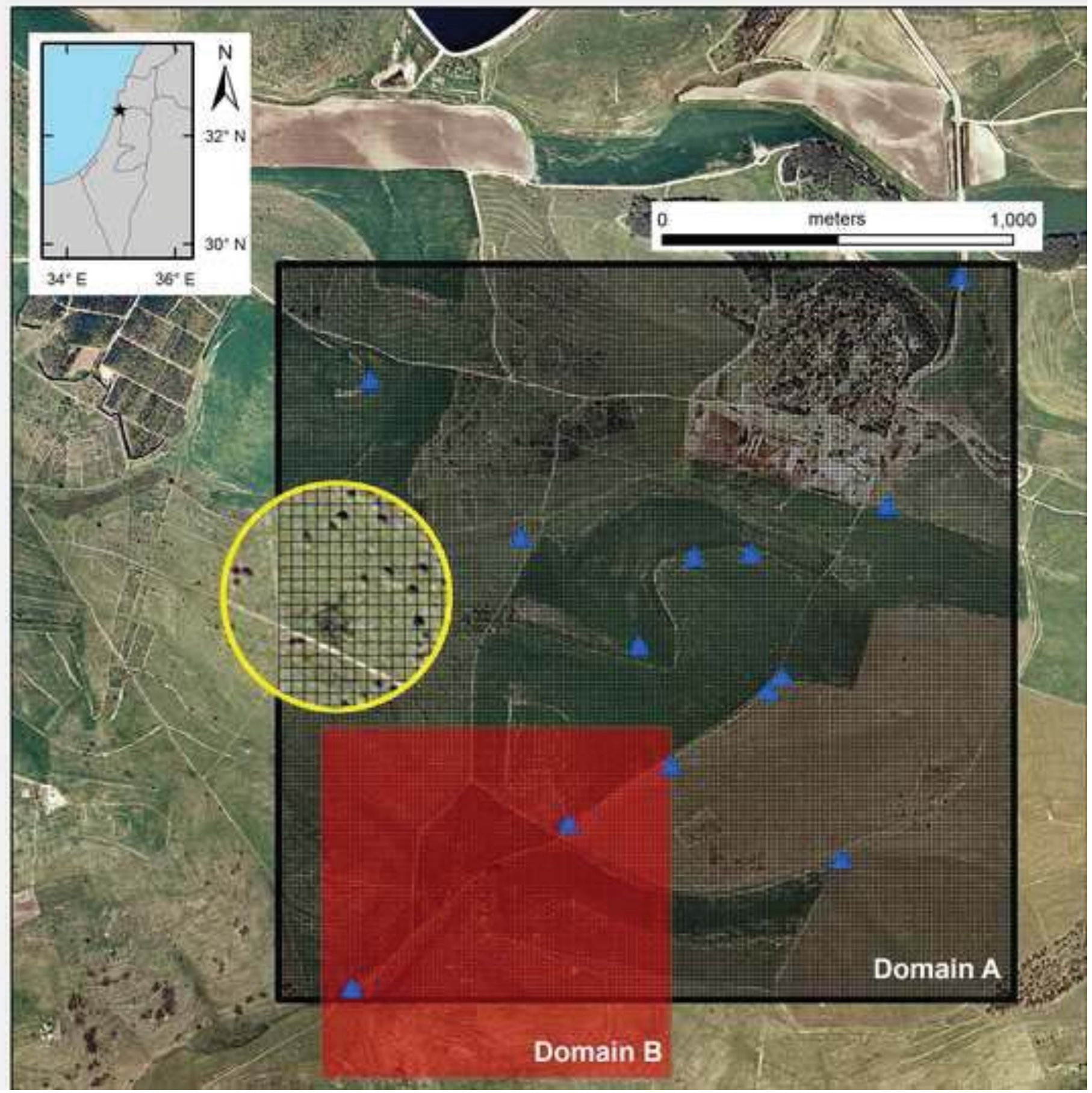



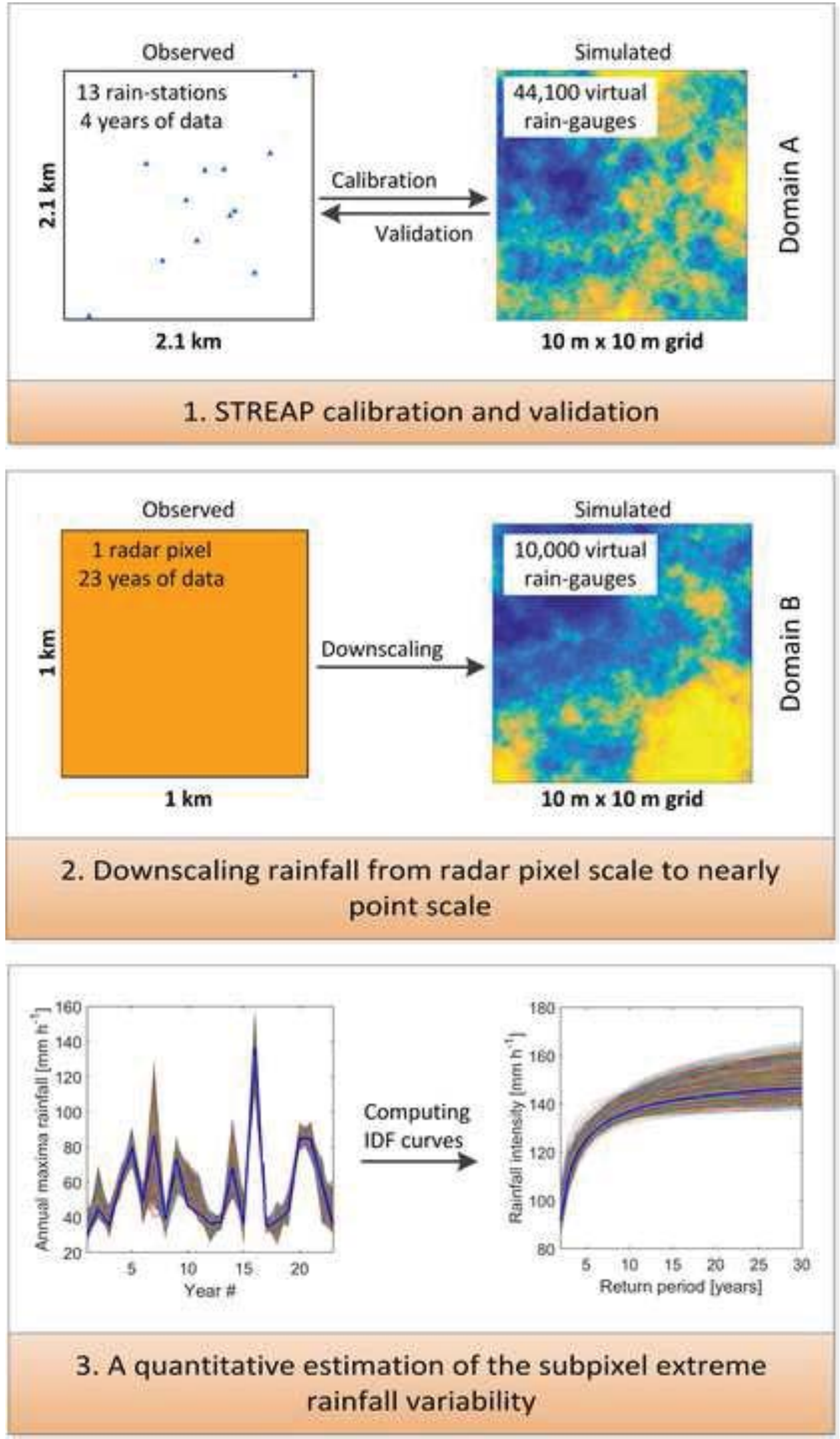

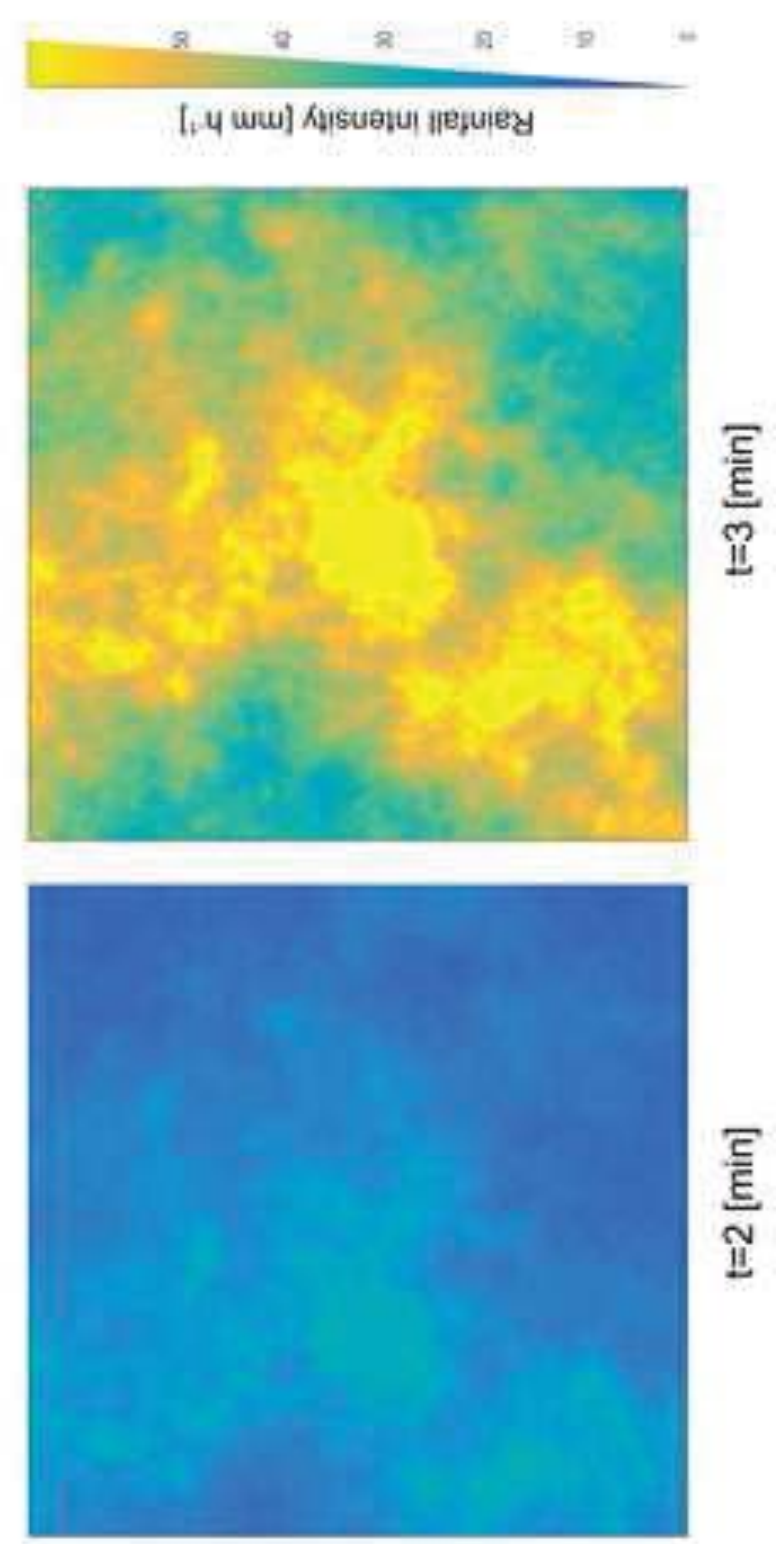

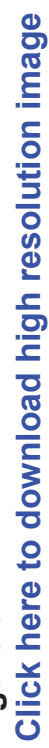

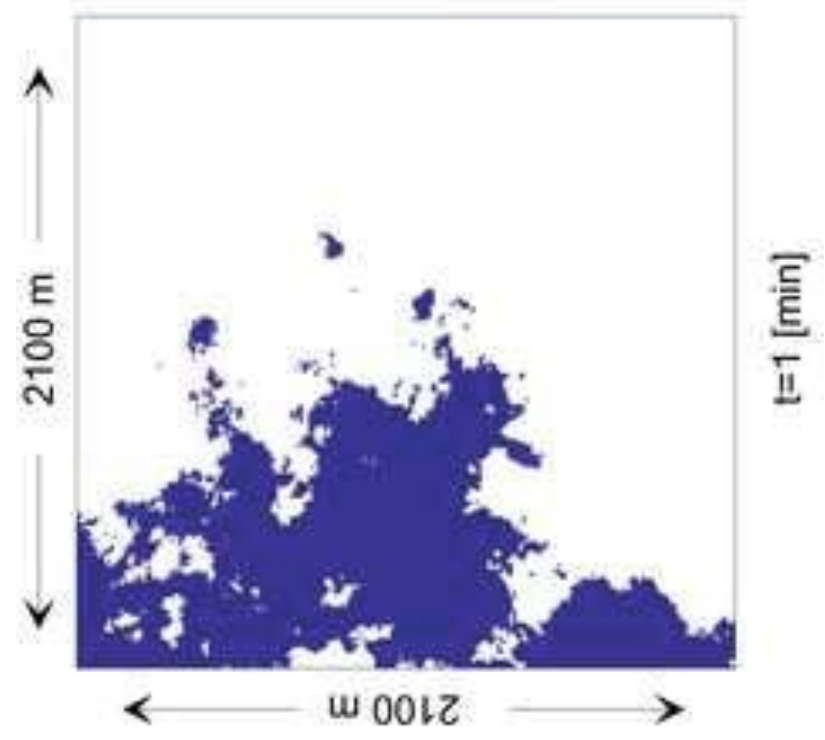


Click here to download high resolution image
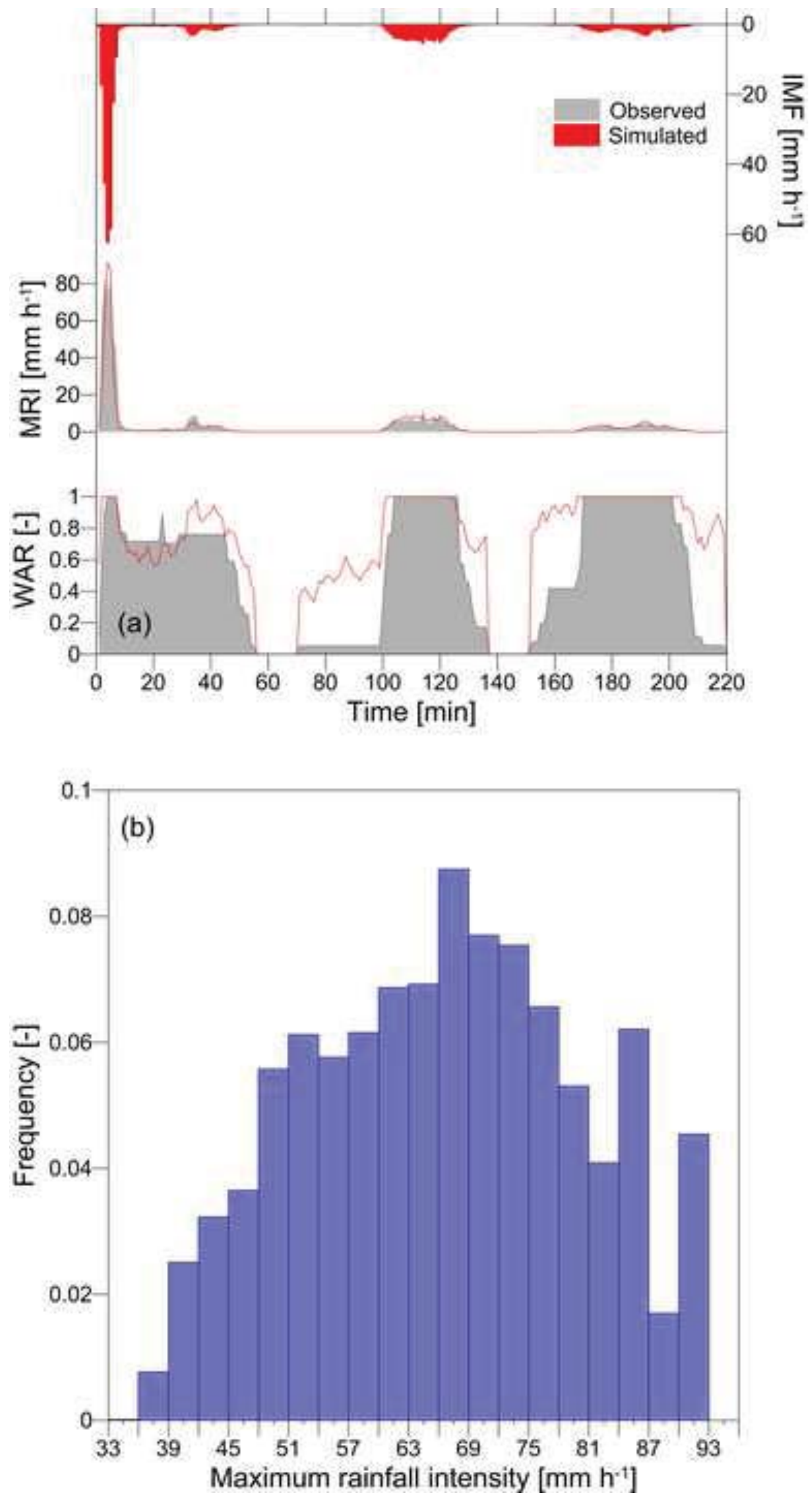


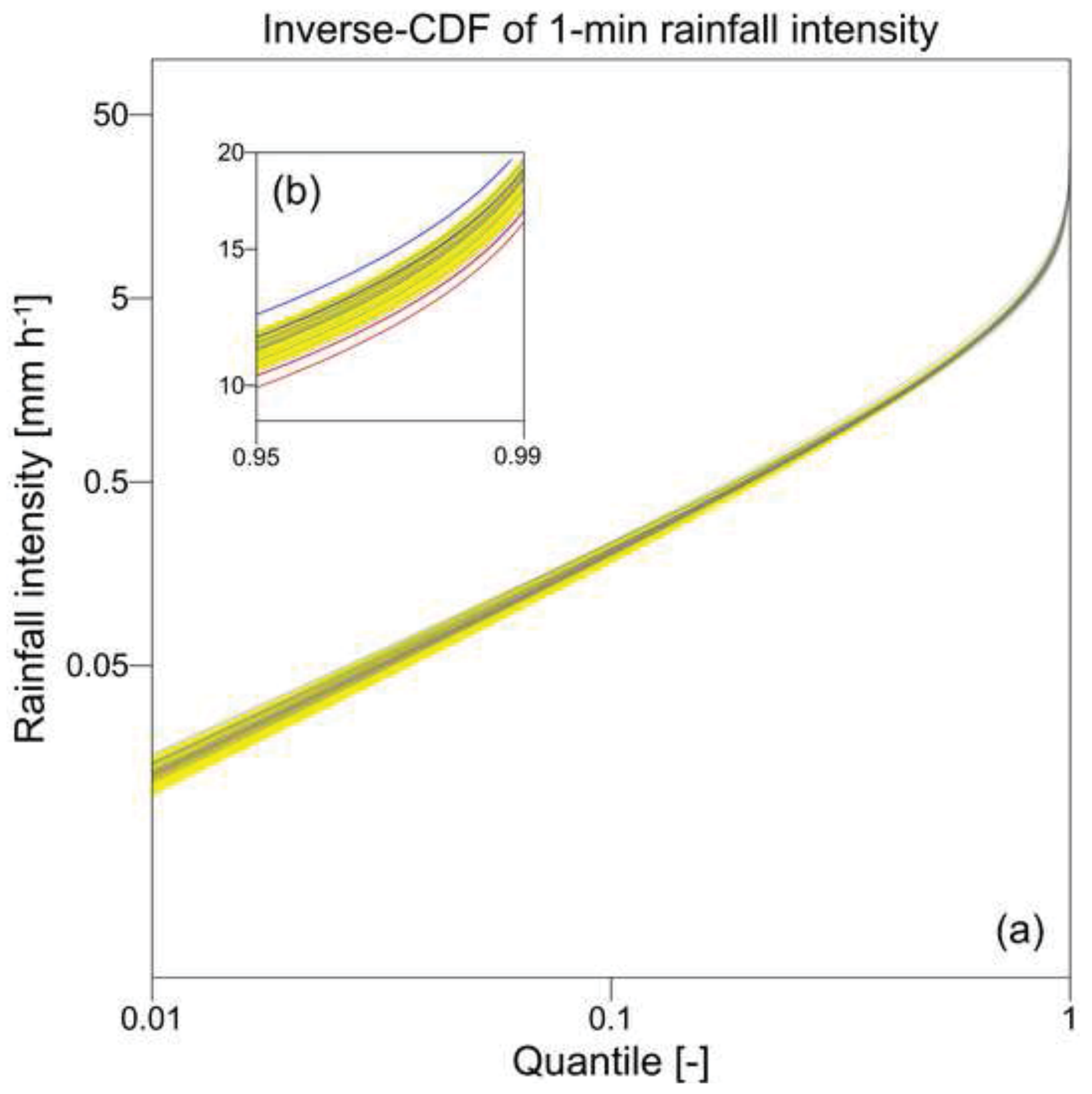



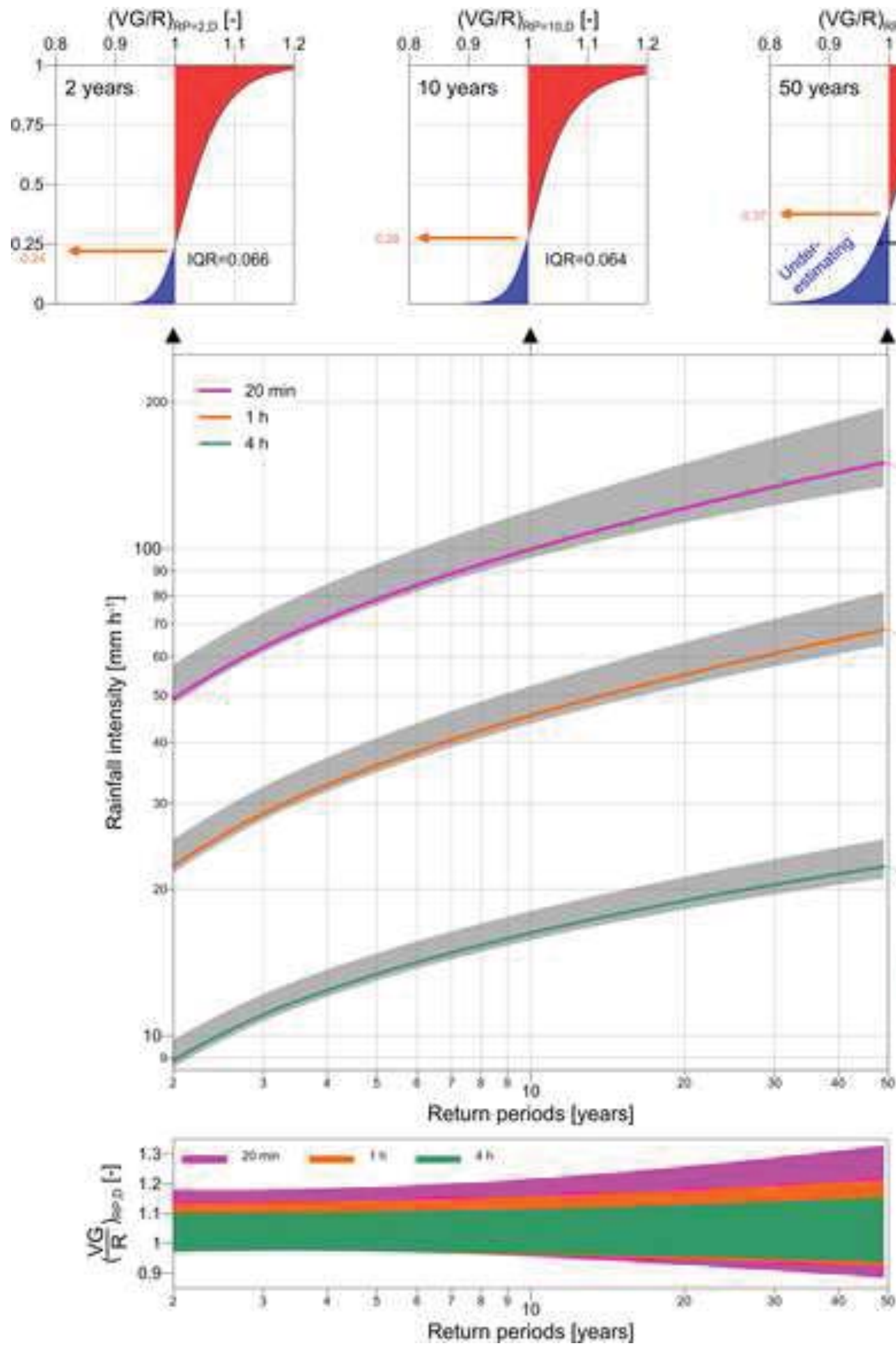
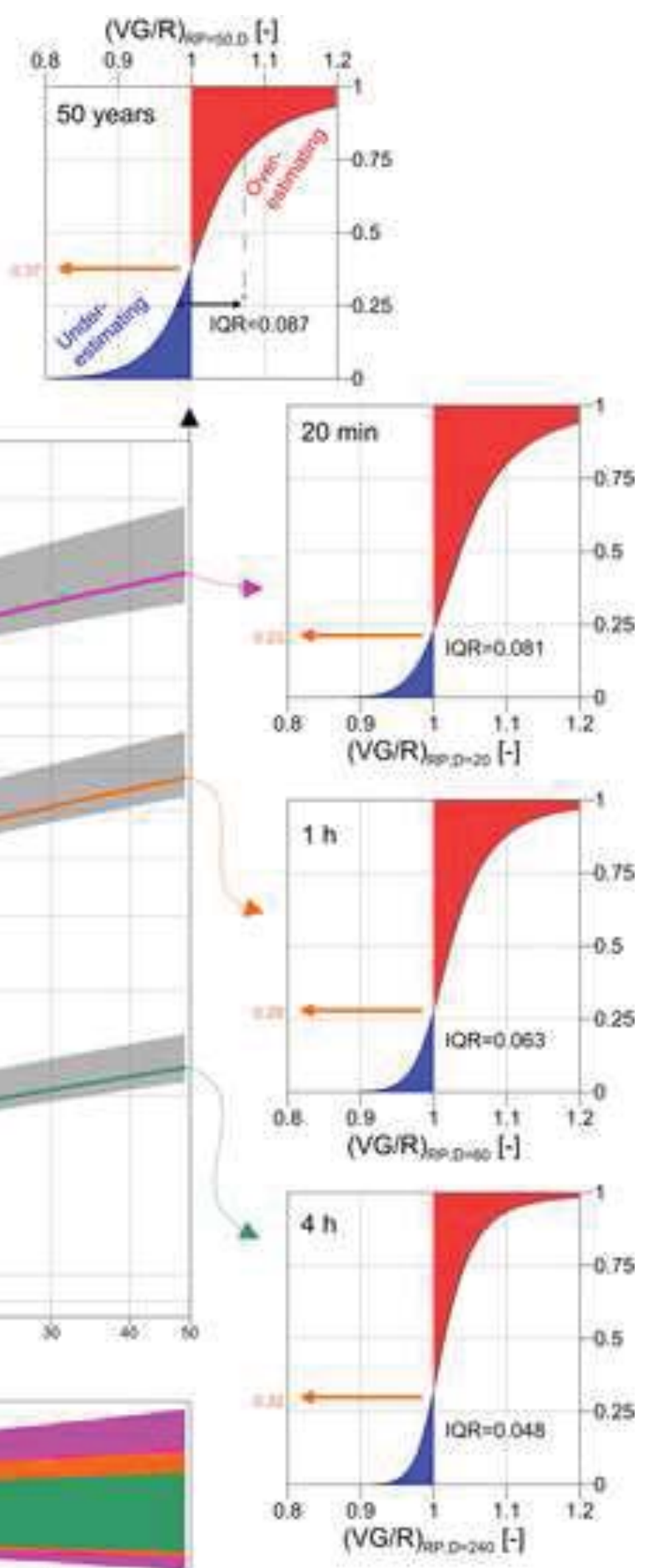


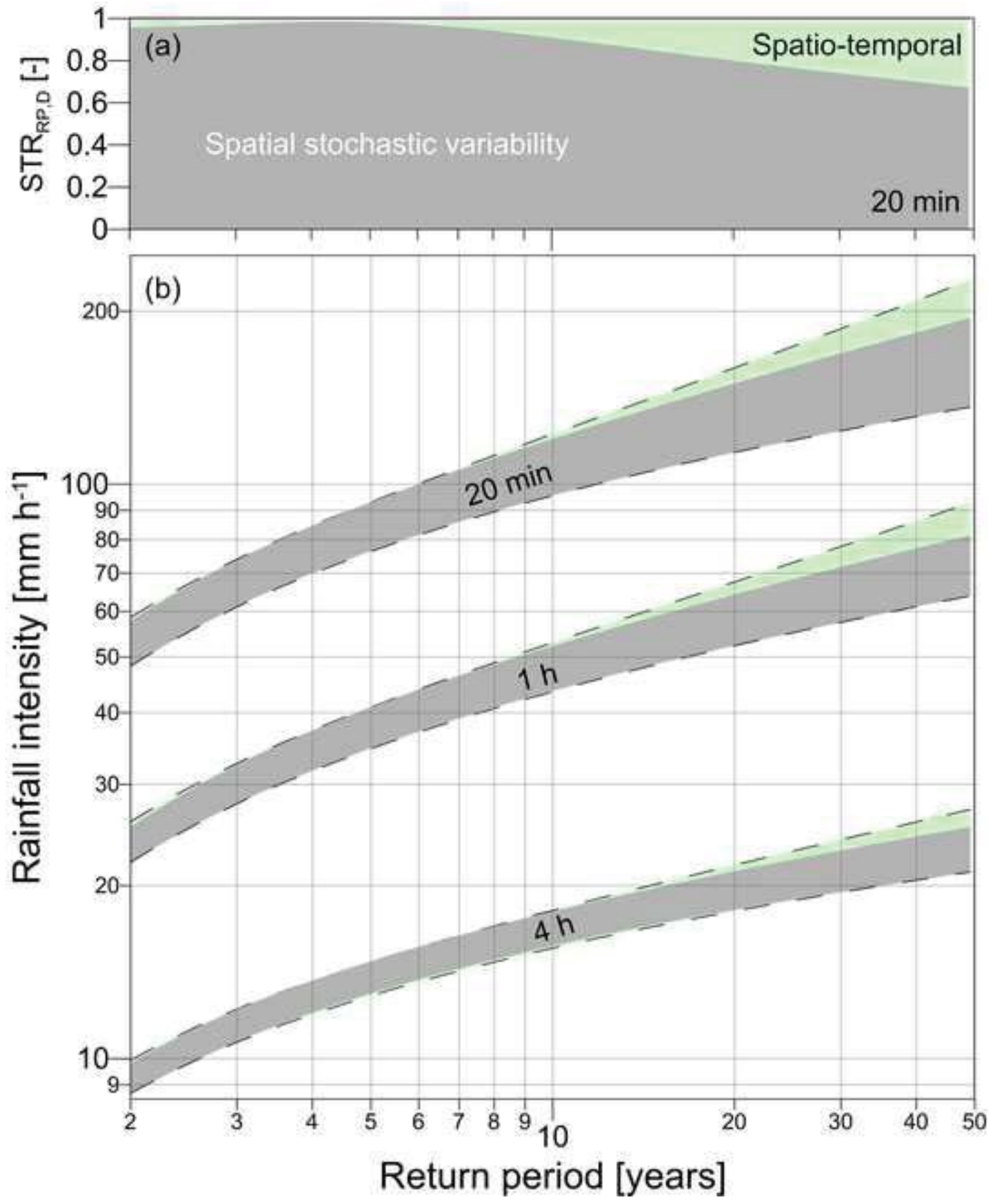




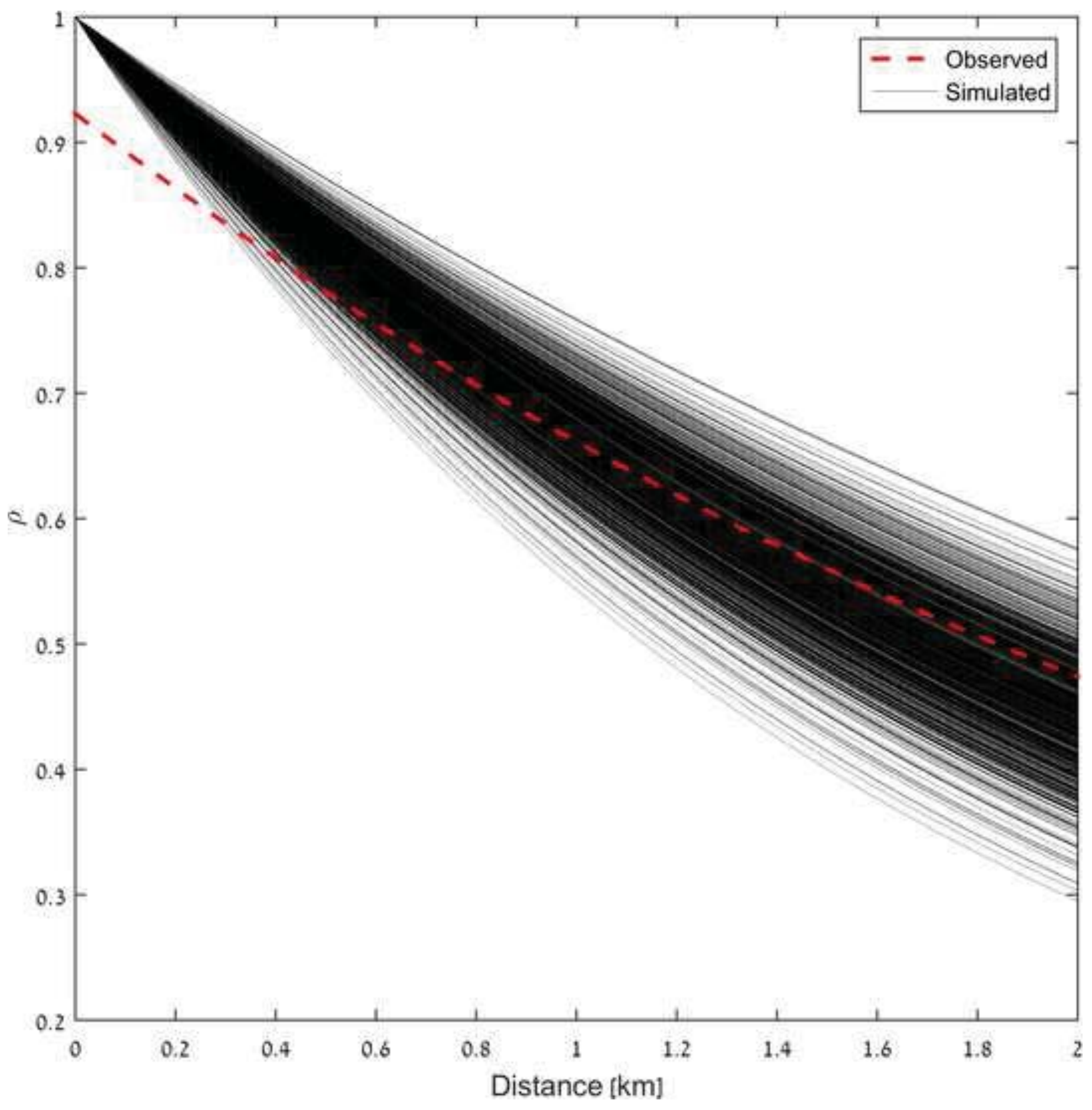




\section{Supplementary Materials}

S1 Rainfall spatial autocorrelation indices

The focus in this study is on the rainfall extreme, thus it was of important to calculate the spatial autocorrelation for each 1-min interval and evaluate it as a function of the corresponding rainfall maxima i.e., validating that the spatial structure of the rainfall is not dependent on the instantaneous maximum rain intensity.

Two indices were used to evaluate the spatial autocorrelation during a rainfall event: the Geary's C index, which is sensitive to local spatial autocorrelation (i.e., comparing rainfall intensity between rain stations), and the Moran's I index, which is sensitive to global spatial autocorrelation (i.e., comparing rain intensity between a rainstation and the mean). A summary of the two indices was given by Goodchild (1986).

The Geary's C index was given by Geary (1954):

$C(t)=\frac{(N(t)-1) \sum_{i} \sum_{j} w_{i j}(t)\left(X_{i}(t)-X_{j}(t)\right)^{2}}{2 \sum_{i} \sum_{j} w_{i j}(t) \sum_{i}\left(X_{i}(t)-\bar{X}(t)\right)^{2}}$

where $t$ is the time step, $N$ is the number of rain stations that were recording at time $t, X_{i}$ and $X_{j}$ are the rainfall intensity recorded by stations $i$ and $j$ accordingly, $\bar{X}$ is the mean rainfall intensity and $w_{i j}$ is a matrix of spatial weights given in the form of the inverse distance between stations $i$ and $j$.

The Moran I index was given by Moran (1948): 
$I(t)=\frac{N(t) \sum_{i} \sum_{j} w_{i j}(t)\left(X_{i}(t)-\bar{X}(t)\right)\left(X_{j}(t)-\bar{X}(t)\right)}{\sum_{i} \sum_{j} w_{i j}(t) \sum_{i}\left(X_{i}(t)-\bar{X}(t)\right)^{2}}$

where $t, N, X_{i}, \bar{X}$ and $w_{i j}$ are equal to the one in Eq (S.2).

The value of Geary's $C$ lies between 0 and 2, where 1 indicate no spatial autocorrelation, values smaller than 1 indicate positive spatial autocorrelation and values larger than 1 indicate negative spatial autocorrelation. The value of Moran's I lies between -1 and 1, where 0 marks no spatial autocorrelation, values larger than 0 indicate positive spatial autocorrelation and values smaller than 0 mean negative spatial autocorrelation.

The indices were calculated for the 1-min rainfall data derived from the dense rain-gauge network and then plotted against the corresponding maximum rain intensity. This was done in order to validate the assumption that the rainfall's spatial structure is not depended in the instantaneous rain intensity. The mean and standard deviation of the indices were calculated and plotted in Fig. S1 (data was binned using $3 \mathrm{~mm} \mathrm{~h}^{-1}$ intervals). It was found that the rainfall local spatial structure remains slightly negative $(C \approx 0.6)$ while the global spatial structure indicates a spatial independence $(I \approx 0)$ for the entire range of maximum rain intensities, thus no dependence was found between the instantaneous maximum rain intensity and the spatial structure of the rainfall.

S2 Estimating small scale rainfall characteristics using the weather radar 
The rainfall coefficient of variation (CV) and the temporal evolution of the rainfall fields (ARMA process of rainfall field in the Lagrangian system of reference) have parameters that could not be estimated directly from the dense rain-gauge network. For the CV estimation an even denser network of rain-gauges would be required within the domain to better represent the rainfall standard deviation, while for estimating the temporal evolution of the rainfall field a gridded rainfall data for the domain would be required. The parameters of the ARMA model and CV were estimated using the weather radar.

The rainfall CV was calculated for domain areas ranging from $6-60 \mathrm{~km}^{2}$ around the rain-gauge network (Fig. S3). Using similar scaling concept as suggested by Schleiss et al. (2011), a power function of $C V=0.13 * A r e a^{0.38}$ was fitted to the data with an $R^{2}$ value of 0.95 and from this function an estimated CV of 0.13 was extrapolated for the $1 \mathrm{~km}^{2}$ domain. Note that the sub-domain grid used to compute the spatial CV is the same for all domain areas and fixed by the radar resolution $\left(1 \mathrm{~km}^{2}\right)$. A similar decrease of rainfall CV as a function of domain area was presented by Sassi et al. (2014). Although the raingauges are likely too sparse, an assessment of the $\mathrm{CV}$ derived directly from the rain-gauge network yield an estimated $\mathrm{CV}$ of 0.23 . Therefore, the range of rainfall $\mathrm{CV}$ was set between 0.13 and 0.23 .

The temporal evolution of the rainfall field is following the field motion. Estimating the ARMA parameters is a difficult and uncertain task. The advection of the rainfall field (field velocity and direction) are not stationary over time and the rainfall field is prone to rotation, convergence and divergence. Paschalis (2013) suggested to use a storm tracking algorithm to identify storms that are moving approximately constantly and then to 
estimate the ARMA parameters by using a constrained least square fitting procedure of the theoretical autocorrelation function of the ARMA process. Paschalis et al. (2013) used an $\operatorname{ARMA}(2,2)$ model for rainfall data analyzed in Switzerland, but stated that different orders of the ARMA model are expected in other locations. In order to estimate the ARMA process for the domains A and B (i.e., for 1-min and $4 \mathrm{~km}^{2}$ or $1 \mathrm{~km}^{2}$, respectively) we used Paschalis (2013) estimating procedure for the weather radar data (5-min temporal resolution and $16-57 \mathrm{~km}^{2}$ spatial resolution); the results of the first 5 spatial scales are presented in Fig. S3. Smaller scales cannot be examined, as not enough data would be available for a proper estimation. For the smallest scales that were examined $\left(16-20 \mathrm{~km}^{2}\right)$ an autocorrelation value of 0.9 for all spatial lags was computed. We therefore expect that the autocorrelation function will show similar or higher values for the smaller domains. Here, we assume an $A R(1)$ model with correlation coefficient in the range $0.85-0.95$.

\section{References}

Geary, R.C., 1954. The Contiguity Ratio and Statistical Mapping. The Incorporated Statistician, 5(3): 115-146. DOI:10.2307/2986645

Goodchild, M.F., 1986. Spatial autocorrelation, 47. Geo Books.

Moran, P.A.P., 1948. The Interpretation of Statistical Maps. Journal of the Royal Statistical Society. Series B (Methodological), 10(2): 243-251. DOI:10.2307/2983777 
Paschalis, A., 2013. Modelling the space-time structure of precipitation and its impact on basin response, Zürich : ETH, 1 Band pp. DOI:10.3929/ethz-a-009917135

Paschalis, A., Molnar, P., Fatichi, S., Burlando, P., 2013. A stochastic model for highresolution space-time precipitation simulation. Water Resources Research, 49(12): 8400-8417. DOI:10.1002/2013WR014437

Peleg, N., Morin, E., 2012. Convective rain cells: Radar-derived spatiotemporal characteristics and synoptic patterns over the eastern Mediterranean. Journal of Geophysical Research: Atmospheres, 117(D15): n/a-n/a. DOI:10.1029/2011JD017353

Peleg, N., Ben-Asher, M., Morin, E., 2013. Radar subpixel-scale rainfall variability and uncertainty: lessons learned from observations of a dense rain-gauge network. Hydrol. Earth Syst. Sci., 17(6): 2195-2208. DOI:10.5194/hess-17-2195-2013

Sassi, M.G., Leijnse, H., Uijlenhoet, R., 2014. Sensitivity of power functions to aggregation: Bias and uncertainty in radar rainfall retrieval. Water Resources Research, 50(10): 8050-8065. DOI:10.1002/2013WR015109

Schleiss, M., Jaffrain, J., Berne, A., 2011. Statistical analysis of rainfall intermittency at small spatial and temporal scales. Geophysical Research Letters, 38(18): n/a-n/a. DOI:10.1029/2011GL049000 


\section{Figures caption}

Fig S1. Geary's C and Moran's I indexes as a function of 1-min maximum rain intensity. The value of Geary's C lies between 0 and 2 ( 1 - no spatial autocorrelation, <1 positive spatial autocorrelation and $>1$ negative spatial autocorrelation). The value of Moran's I lies between -1 and 1 ( 0 - no spatial autocorrelation, >0 positive spatial autocorrelation and $<0$ negative spatial autocorrelation). The numbers above the points represent the number of observations in each bin.

Fig S2. Lognormal distribution fitted to the rainfall intensity on a typical convective radar image [22/12/1999 22:50, data obtained from the analysis presented by Peleg and Morin (2012)].

Fig S3. Rainfall coefficient of variation (CV) and temporal correlation coefficient $(A R(1))$ fit and prediction at different spatial scales as obtained from the weather radar. 


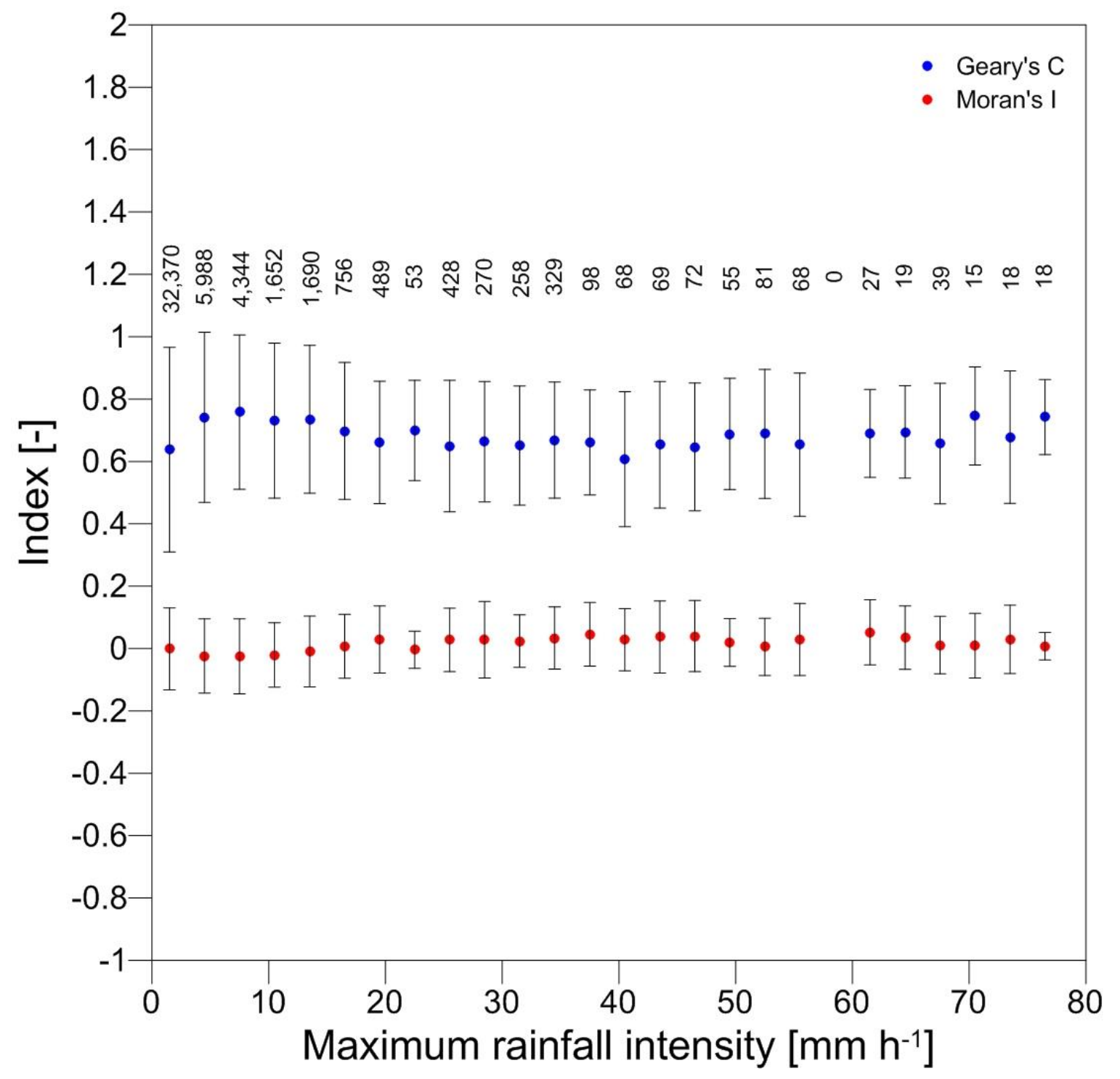




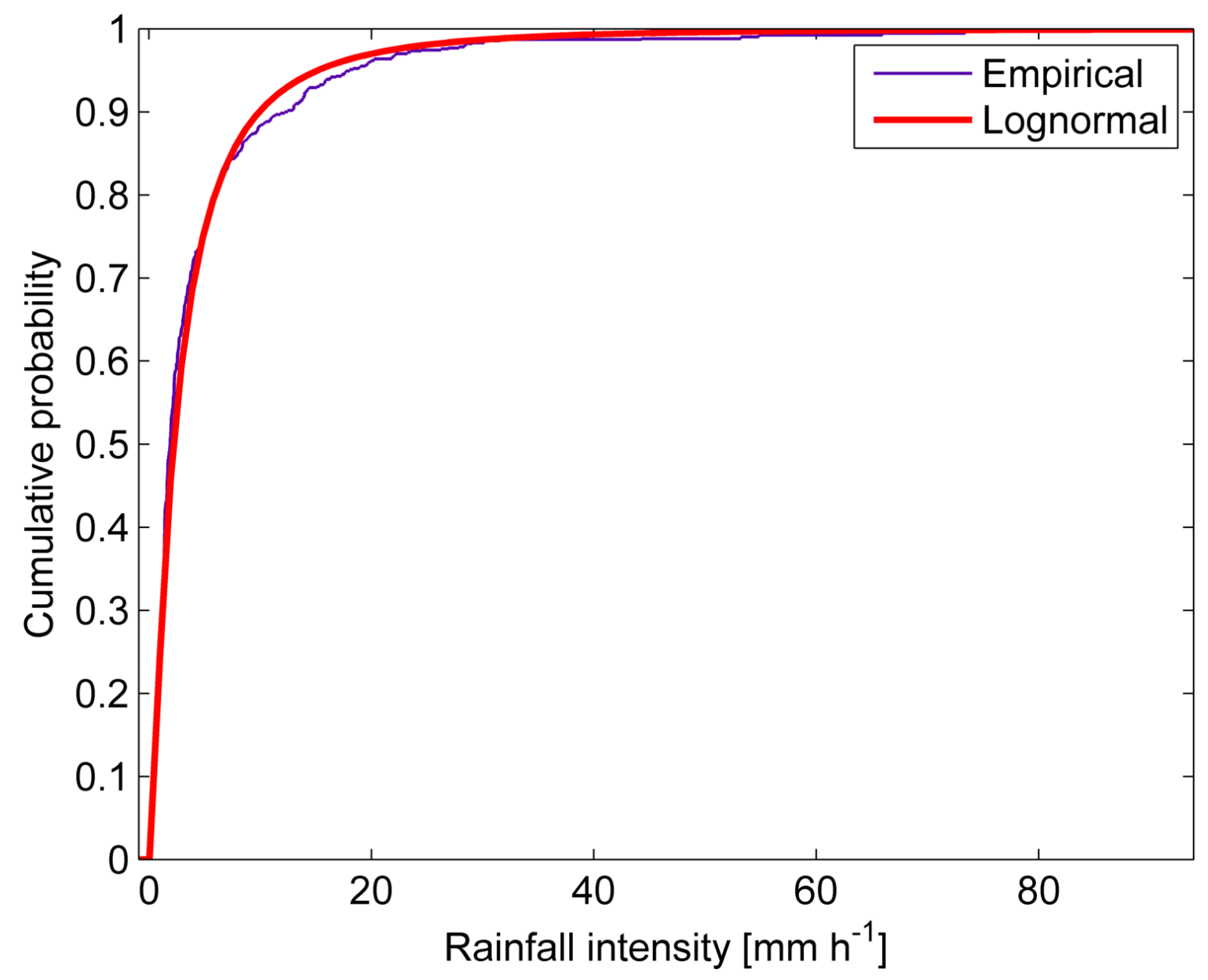




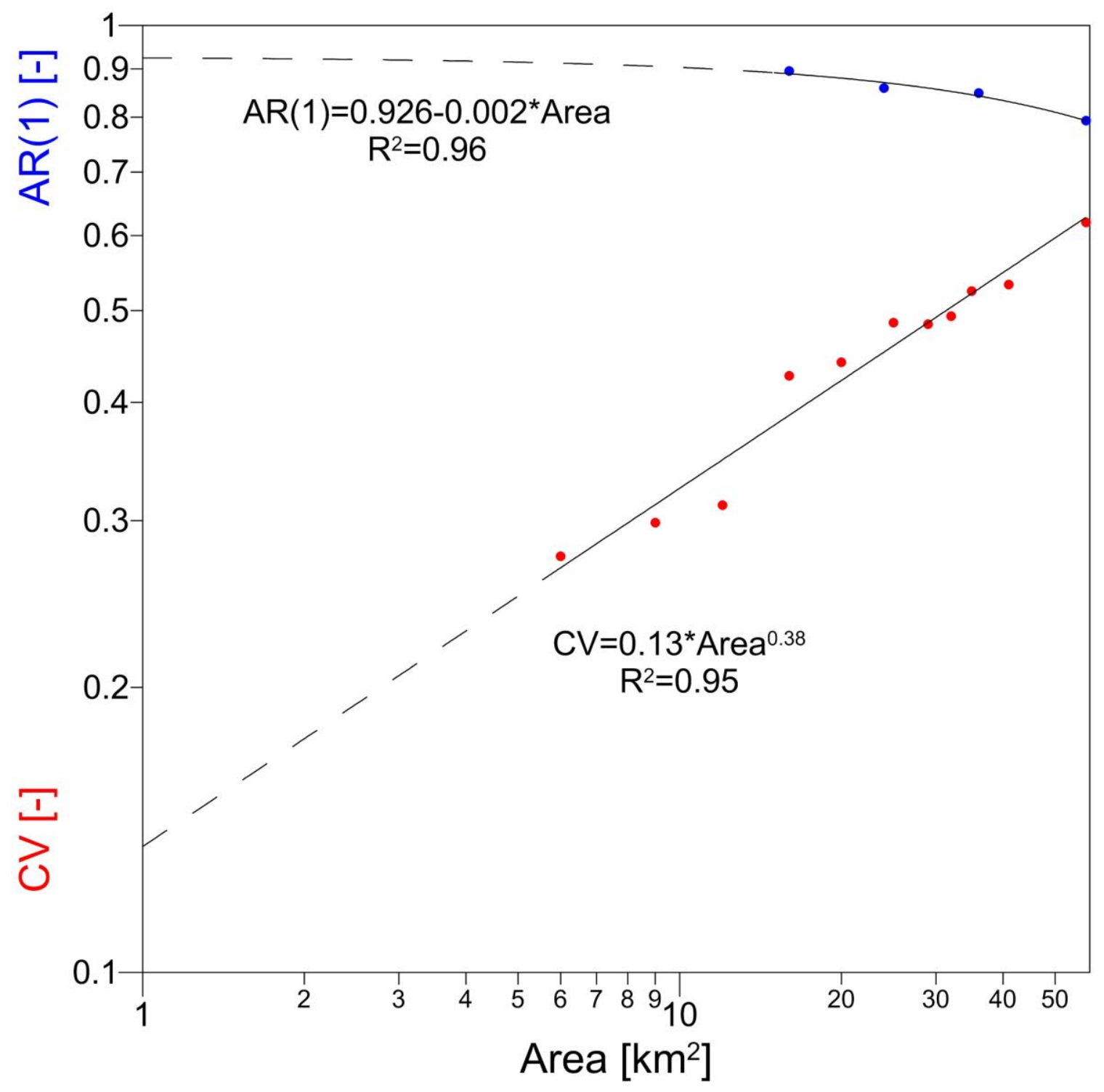

